\title{
Evaluation of CryoSat-2 derived sea-ice freeboard over fast ice in McMurdo Sound, Antarctica
}

\author{
D. PRICE, ${ }^{1}$ J. BECKERS, ${ }^{2}$ R. RICKER, ${ }^{3}$ N. KURTZ, ${ }^{4}$ W. RACK, ${ }^{1}$ C. HAAS, ${ }^{5}$ V. HELM, ${ }^{3}$ \\ S. HENDRICKS, ${ }^{3}$ G. LEONARD, ${ }^{6}$ P.J. LANGHORNE ${ }^{7}$ \\ ${ }^{1}$ Gateway Antarctica, University of Canterbury, Christchurch, New Zealand \\ ${ }^{2}$ Department of Earth \& Atmospheric Sciences, University of Alberta, Edmonton, Alberta, Canada \\ ${ }^{3}$ Alfred Wegener Institute Helmholtz Centre for Polar and Marine Research, Bremerhaven, Germany \\ ${ }^{4}$ Cryospheric Sciences Laboratory, NASA Goddard Space Flight Center, Greenbelt, MD, USA \\ ${ }^{5}$ Department of Earth, Space Science and Engineering, York University, Toronto, Ontario, Canada \\ ${ }^{6}$ School of Surveying, University of Otago, Dunedin, New Zealand \\ ${ }^{7}$ Department of Physics, University of Otago, Dunedin, New Zealand \\ Correspondence: D. Price <daniel.price@pg.canterbury.ac.nz>
}

\begin{abstract}
Using in situ data from 2011 and 2013, we evaluate the ability of CryoSat-2 (CS-2) to retrieve sea-ice freeboard over fast ice in McMurdo Sound. This provides the first systematic validation of CS-2 in the coastal Antarctic and offers insight into the assumptions currently used to process CS-2 data. European Space Agency Level 2 (ESAL2) data are compared with results of a Waveform Fitting (WfF) procedure and a Threshold-First-Maximum-Retracker-Algorithm employed at $40 \%$ (TFMRA40). A supervised freeboard retrieval procedure is used to reduce errors associated with sea surface height identification and radar velocity in snow. We find ESAL2 freeboards located between the ice and snow freeboard rather than the frequently assumed snow/ice interface. WfF is within $0.04 \mathrm{~m}$ of the ice freeboard but is influenced by variable snow conditions causing increased radar backscatter from the air/snow interface. Given such snow conditions and additional uncertainties in sea surface height identification, a positive bias of $0.14 \mathrm{~m}$ away from the ice freeboard is observed. TFMRA40 freeboards are within $0.03 \mathrm{~m}$ of the snow freeboard. The separation of freeboard estimates is primarily driven by the different assumptions of each retracker, although waveform alteration by variations in snow properties and surface roughness is evident. Techniques are amended where necessary, and automatic freeboard retrieval procedures for ESAL2, WfF and TFMRA40 are presented. CS-2 detects annual fastice freeboard trends using all three automatic procedures that are in line with known sea-ice growth rates in the region.
\end{abstract}

KEYWORDS: remote sensing, sea ice, sea-ice growth and decay

\section{INTRODUCTION}

Although Antarctic sea-ice extent and concentration have been routinely monitored since 1979 (Parkinson and Cavalieri, 2012), the spatial and temporal distribution of sea-ice thickness remains one of the least understood physical components of the global cryosphere (Vaughan and others, 2013). Quantification of thickness is of crucial importance, since when combined with areal data it allows the computation of sea-ice volume. Sea-ice volume provides insight into the heat budget of the Antarctic sea-ice system and quantification of freshwater and saltwater fluxes in the Southern Ocean. Due to the scarcity of in situ measurements of Antarctic sea-ice thickness, there is great demand for improved temporal and spatial thickness data through satellite altimeter observations (Zwally and others, 2008; Yi and others, 2011; Kurtz and Markus, 2012; Xie and others, 2013). Such observations support the capability to monitor trends and in turn provide data to model forecasts of future Antarctic sea-ice properties (Massonnet and others, 2013; Holland and others, 2014).

The use of satellite altimetry for sea-ice thickness estimation is entirely reliant upon the measurement of freeboard (Fig. 1). Following this, thickness can be estimated based on the assumptions of hydrostatic equilibrium given input of values for the densities of snow, ice, water and snow thickness (Alexandrov and others, 2010). The ability to accurately measure freeboard and to include information on snow morphology is vital, as any errors in these input factors are greatly magnified in the eventual sea-ice thickness estimation. The European Space Agency's (ESA) Synthetic aperture radar Interferometric Radar ALtimeter system (SIRAL) on-board CryoSat-2 (CS-2) is the most advanced satellite radar altimeter instrument for sea-ice freeboard retrieval in operation to date (Drinkwater and others, 2004; Wingham and others, 2006), and at the time of writing is improving understanding of the Arctic sea-ice thickness distribution (Laxon and others, 2013; Kurtz and others, 2014; Ricker and others, 2014). Given the more heterogeneous and thinner state of Antarctic sea ice, primarily due to its exposed oceanic setting and its highly variable snow distribution and morphology (Massom and others, 2001; Ozsoy-Cicek and others, 2013), the uncertainty in resultant thickness estimates from CS-2 in the Southern Ocean is likely to be higher.

In this study, we validate freeboard measurements from CS-2 over fast ice in McMurdo Sound in 2011 and 2013. The fast ice in this area provides a safe platform for the collation of in situ data (Price and others, 2014), and the area has been well investigated (Jeffries and others, 1993; Gow and others, 1998; Leonard and others, 2006; Dempsey and others, 2010; Mahoney and others, 2011; Gough and others, 2012; Smith 


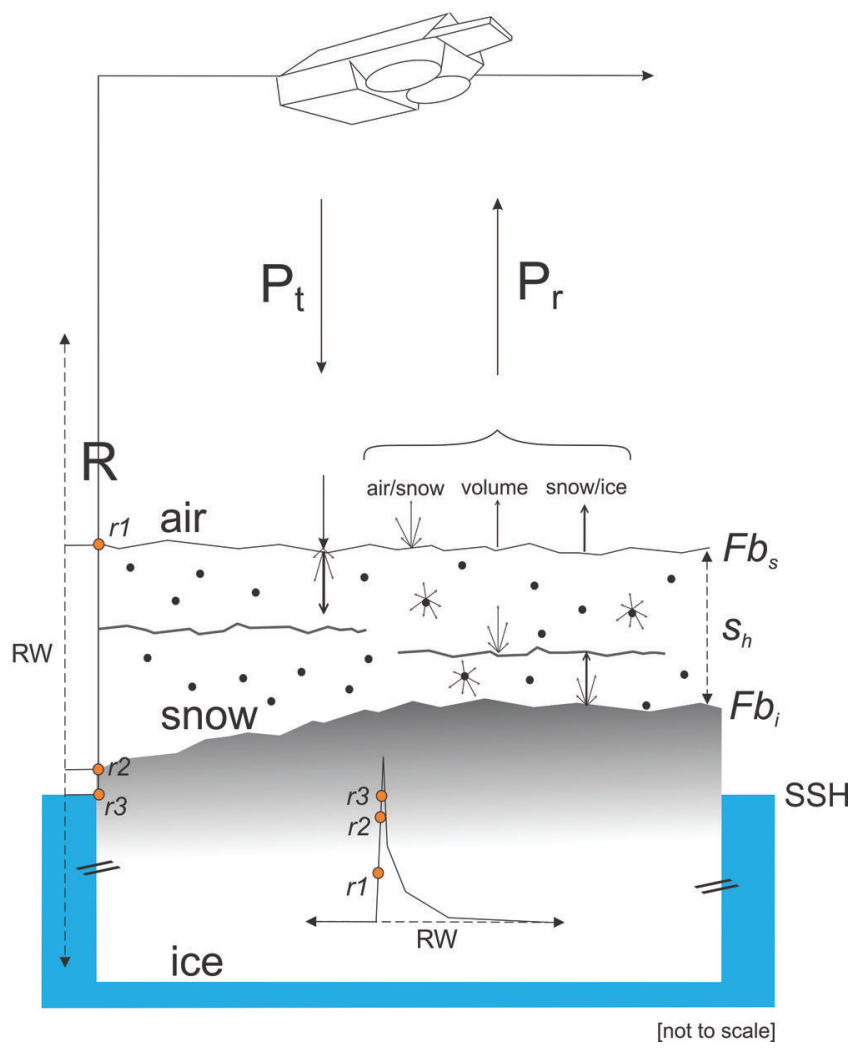

Fig. 1. Components relating to the interpretation of CryoSat-2 freeboard data. The reception period is maintained by a range window (RW; $120 \mathrm{~m}$ in SIN mode) which is constantly adjusted in the vertical dimension to receive echoes from the surface. The transmitted power $\left(P_{\mathrm{t}}\right)$ is subject to interaction at the surface from the air/snow interface, volume of the snow cover and snow/ice interface which all influence the power returned to the satellite $\left(P_{\mathrm{r}}\right)$. The dominant backscattering surface is variable and is displaced by varying snow depth $\left(s_{h}\right)$, snow layering and snow and ice properties. The retracking procedure is completed, resulting in a range $(R)$ between $r 1$ and $r 2$ over sea ice ( $r 3$ over water) dependent upon the assumptions of the respective retracking technique. This range is subtracted from the satellite altitude above the ellipsoid to provide uncorrected height. After application of geophysical corrections, freeboard is obtained by discerning the difference between local sea surface height ( $\mathrm{SSH}$ ) and an interface in the range of the ice freeboard $\left(\mathrm{Fb}_{\mathrm{i}}\right)$ and the snow freeboard $\left(\mathrm{Fb}_{\mathrm{s}}\right)$ as measured by the satellite.

and others, 2012). The sea ice in McMurdo Sound is largely uniform and level, with smooth gradients in thickness. The complexity in view of satellite validation is significantly reduced in comparison to the more dynamic pack ice conditions. In common with many other coastal Antarctic regions (Fedotov and others, 1998; Fraser and others, 2011) McMurdo Sound harbors extensive areas of fast-ice neighboring coastal polynyas and ice shelves as regions of significant sea-ice production (Massom and others, 1998; Tamura and others, 2008). The performance of radar altimeters for freeboard retrieval in these regions of highly variable ocean conditions is yet to be evaluated, specifically with regard to sea-ice/water discrimination over differing surface types (i.e. leads and polynyas of varying sizes).

Compared to ICESat (the Ice, Cloud and land Elevation Satellite; infrared laser shots with $70 \mathrm{~m}$ footprints every $170 \mathrm{~m}$ along track), the CS-2 radar signal penetrates cloud cover but produces a larger footprint of $\sim 380 \mathrm{~m} \times 1650 \mathrm{~m}$ dependent upon orbit parameters and surface geometry
(Bouzinac, 2013). Freeboard retrieval using laser instrumentation is simplified by the fact that the main reflection from the snow surface is well defined. In Ku band (SIRAL center frequency $13.6 \mathrm{GHz}$ ) the backscattered radar energy is more susceptible to alteration from surface conditions, but the main reflection is assumed to originate primarily from the snow/ice interface (Laxon and others, 2013). A recent simulation suggests that the influence of snow on sea ice is not negligible as it can broaden the waveform of the returned signal, thus displacing the tracking point (corresponding to the retrieved surface height) toward the altimeter (Kwok, 2014). The influence of snow on the shape of the returned waveform depends on its dielectric properties which are dictated by salinity, liquid water content, density, grain size and temperature (Hallikainen and others, 1986; Ulaby and others, 1986; Barber and others, 1995).

Given the complex snow stratigraphy and snow microwave interaction, there is no consensus on a dominant backscattering surface. For example, no single dominant backscattering surface was found for stratified snow during in situ investigations using a $10-16 \mathrm{GHz}$ band instrument, but returns from the snow/ice interface dominated when layering in the snow cover was absent (Willatt and others, 2010). Surface roughness also influences the freeboard retrieval as it directly affects the shape of the returning radar waveform (Drinkwater, 1991; Beaven and others, 1995; Hendricks and others, 2010). Surface roughness may be separated into radar and geometric roughness: the former is associated with small-scale features at length scales comparable to the radar wavelength (in this case $0.02 \mathrm{~m}$ ), and the latter is concerned with large-scale surface undulations (e.g. ridging and cracks). The bandwidth of the compressed high-intensity radar pulse (chirp) of SIRAL $(320 \mathrm{MHz})$ results in a range resolution of $0.47 \mathrm{~m}$. This can resolve neither the air/snow nor the snow/ice interface, making the identification of surface height highly dependent on the slope of the leading edge of the returned waveform (Fig. 2).

The factors described above exacerbate the accurate localization of a dominant backscattering surface over sea ice, and, in turn, the retracking, a procedure which interprets the waveform to estimate the range to the surface, is complicated (Figs 1 and 2). There are currently two separate approaches using waveform interpretations to establish retracking points: (1) a waveform-fitting approach that takes into account the shape of the returned waveform based on a physical model; and (2) an empirical approach that only considers the leading edge and estimates surface height at a given power threshold. Waveform fitting is the basis for the ESA's Level 2 product (ESAL2) and the Waveform Fitting (WfF) procedure as described by Kurtz and others (2014). The Threshold-First-Maximum-RetrackerAlgorithm employed at $40 \%$ (TFMRA40) is an empirical approach presented by Helm and others (2014) and applied over sea ice by Ricker and others (2014).

In this paper, we assess the assumptions behind the techniques referenced above with a detailed in situ investigation on fast ice in McMurdo Sound. With the addition of Moderate Resolution Imaging Spectroradiometer (MODIS) imagery we undertake a supervised freeboard retrieval procedure in which sea surface height is manually classified on a small number of selected CS-2 tracks. Using this optimal dataset, and additional CS-2 waveform information, we provide insight into the influence of differing surface conditions 


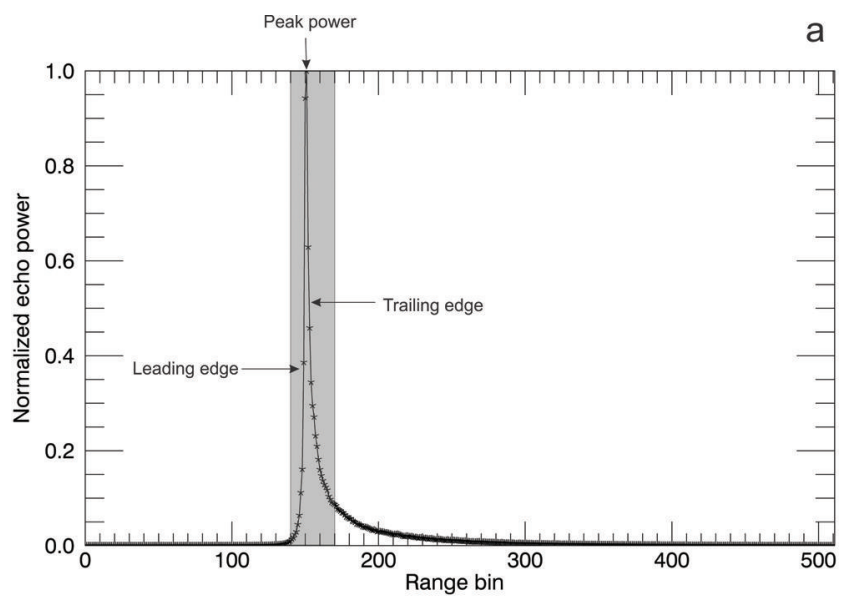

b

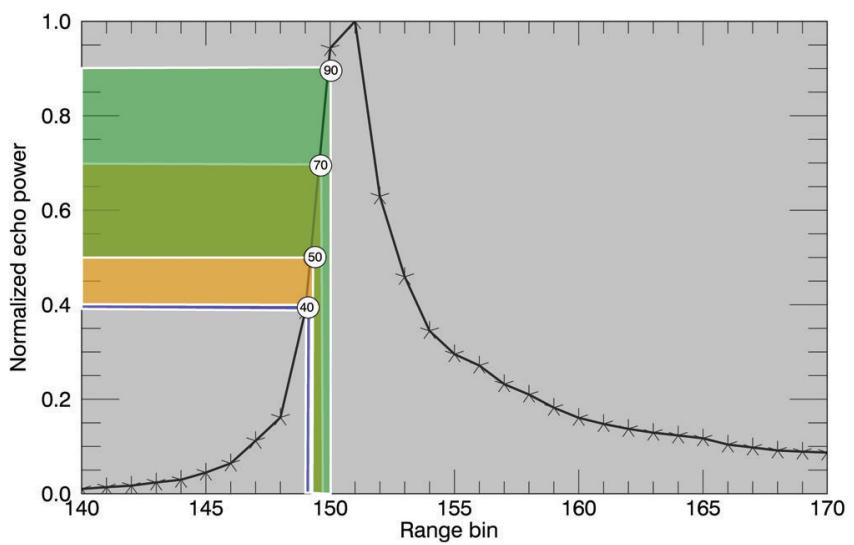

Fig. 2. (a) Typical CryoSat-2 SIN mode waveform over snowcovered sea ice in McMurdo Sound with labelling of characteristics mentioned in the text. (b) An expanded view of the outlined grey area in (a) from range bins $140-170(1$ bin $=0.234 \mathrm{~m})$ and the expected retracking points on the leading edge for the techniques described here: ESAL2 (40-70\% orange), WfF (50-90\% green) and TFMRA40 (40\% blue).

(snow properties and surface roughness) on the resultant freeboards from each technique: ESAL2, WfF and TFMRA40. This supervised analysis also provides information on the estimated accuracy of CS-2 freeboard retrievals over the fast ice in McMurdo Sound. With information gained in an initial evaluation, we subsequently develop three automatic freeboard retrieval procedures and assess the sea-ice regime in McMurdo Sound for the entirety of 2011 and 2013.

First, we describe the study area of McMurdo Sound and in situ information and provide an overview of CS-2 in Section 2. In Section 3, we describe and discuss the surface height retrieval procedure for CS-2 under each technique. In Section 4, we manually identify sea surface height and complete a supervised freeboard retrieval investigation providing freeboard estimates for each technique and report the findings of these results and their implications. Following this, in Section 5, we describe the three automatic algorithms used to assess the years 2011 and 2013 in a larger area of McMurdo Sound. Results from these automated procedures are then reported and discussed in the final sections.

\section{CRYOSAT-2 ASSESSMENT IN MCMURDO SOUND}

This section describes the study area of McMurdo Sound, the in situ investigation and provides an overview of CS-2. The study area (Fig. 3) is located in the southwestern Ross Sea and
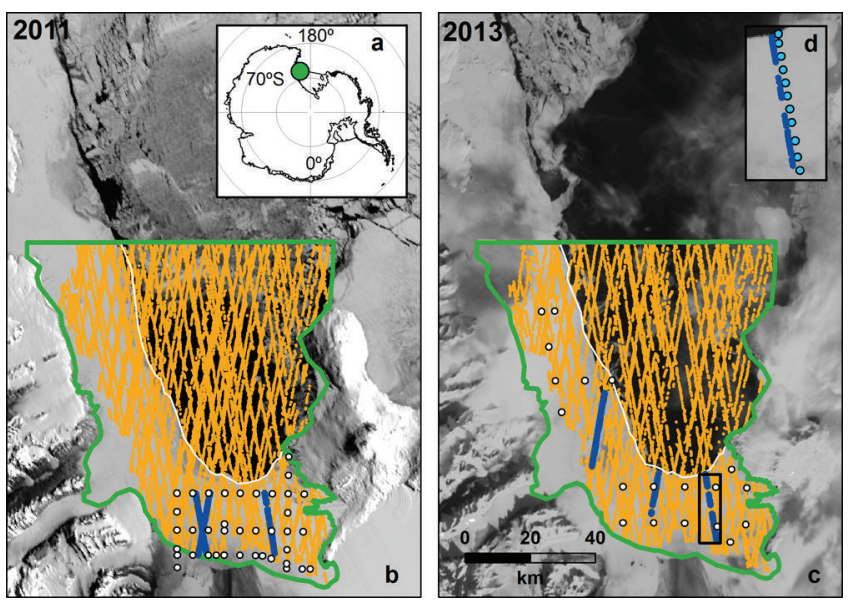

Fig. 3. (a) Location of the study area within the Antarctic. (b, c) McMurdo Sound and the study area for 2011 (b) and 2013 (c), showing the distribution of CryoSat-2 tracks for those used in the supervised analysis (blue lines), the automatic study period (orange lines) and locations of in situ measurement sites (white dots). The November fast-ice edge is displayed for each year (white line). The full study area for each annual automatic analysis is outlined in green. The validation line in Figure 4 is highlighted by the black rectangle and expanded in (d) to show each in situ measurement point (light blue dots) along the CryoSat-2 track.

occupies an area of $\sim 6400 \mathrm{~km}^{2}$. McMurdo Sound's proximity to ice shelves and the outflow of cold ice-shelf water from the ice-shelf cavity contributes to sea-ice formation in this area (Purdie and others, 2006; Dempsey and others, 2010; Mahoney and others, 2011; Gough and others, 2012; Price and others, 2014). This influence is hypothesized to be present in similar settings around the Antarctic with potential basin-wide implications (Hellmer, 2004; Bintanja and others, 2013). At the time of writing, McMurdo Sound harbors a first-year (FY) sea-ice regime with extensive areas of highly homogeneous fast ice in its southern and western extremities and the McMurdo Sound Polynya (MSP) at its center. The MSP undergoes complete freeze-up and breakout events throughout autumn and winter but is typically open water during spring and summer. This open-water area can become intermittently inundated with a cover of sea-ice floes that have drifted south from the Ross Sea.

\subsection{In situ investigations}

During two in situ measurement campaigns in November and December 2011 and 2013, sea-ice freeboard, thickness and snow depth/density measurements were made for comparison with CS-2 freeboard retrievals. The locations of in situ measurements within McMurdo Sound are shown in Figure 3. The in situ measurement campaign in 2011 along with an overview of sea-ice conditions in McMurdo Sound is described in Price and others (2014), and these same measurement procedures were carried out in 2013. Even though the sea-ice conditions in 2013 were very similar to 2011, it is important to note that surface conditions were slightly different with regard to the snow cover and surface roughness. The first of the differences was related to sea-ice deformation. The sea-ice cover was more deformed in the west in 2013, resulting in higher geometric surface roughness. The second notable difference was in the snow cover. In 2011 the snow was characterized as windcompacted, with a large variability in hardness, density and 
grain size. Grain size was generally large near the ice $(\sim 3 \mathrm{~mm})$, and smaller in the upper layers, typically $\sim 0.5 \mathrm{~mm}$ and smaller. Where snow was $0.20 \mathrm{~m}$ in thickness we found two to three layers, with densities varying between 330 and $450 \mathrm{~kg} \mathrm{~m}^{-3}$ with no significant correlation between depth and density. In 2013 a similar situation existed, but both thickness and layering were reduced, while radar roughness was likely higher given a less uniform snow surface at the centimeter scale. In both years the distribution was highly variable, with many different snow types present.

\subsection{CryoSat-2}

Launched in April 2010, CS-2 operates in a near-circular polar orbit with an inclination of $92^{\circ}$ and has a repeat cycle of 369 days with a subcycle of 30 days. Its on-board altimeter, SIRAL, operates at a center frequency of $13.6 \mathrm{GHz}$ and is normal-incidence, with two receiver chains operating in two modes over sea-ice areas (Bouzinac, 2013). Its dedicated sea-ice mode uses synthetic aperture radar (SAR) processing for height retrievals along-track at an improved spatial resolution. In addition, being pulse-limited across track results in a footprint size of approximately $380 \mathrm{~m} \times$ $1650 \mathrm{~m}$, with along-track sampling at $\sim 300 \mathrm{~m}$ intervals permitting enhanced along-track ice/water discrimination and higher sampling (Bouzinac, 2013). In Antarctic coastal regions, SIRAL switches to SAR interferometric (SIN) mode for ice-sheet margin investigation. Interferometric processing discerns the arrival angle of radar returns via phase comparison of the returning signal. This permits them to be correctly positioned on the Earth's surface, and off-nadir returns to be accurately ranged (Wingham and others, 2006; Bouzinac, 2013). This is a necessity in complex terrain, where off-nadir reflections can be received by the satellite prior to nadir reflections. The SIN mask extends out to a maximum distance of $\sim 300 \mathrm{~km}$ from the Antarctic coastline and ice-shelf margins. Due to the study area's proximity to the Antarctic continental coast it falls within the SIN mask. To account for the increased range over which the surface may be encountered by the incident radar beam in complex terrain, a longer tracking window is permitted in SIN mode. At the same time the reduction in burst-repetition frequency decreases the number of resulting measurements by a factor of four compared to SAR mode (Wingham and others, 2006; Bouzinac, 2013). The measurement range window is segmented into 512 bins providing a range sampling of $1.563 \mathrm{~ns}(0.234 \mathrm{~m}$ in vacuo). A CS-2 SIN mode example waveform with labelling relevant to the text is shown in Figure 2. The surface is maintained in a range window along track, which constantly adjusts to keep the leading edge at a specific point near the center of the window (Bouzinac, 2013). Energy from the surface that is returned to the satellite builds above the noise level and increases along the leading edge to the peak power. This then decays (the trailing edge) to the end of the tracking window. The retracking procedure is then used to identify the point on the waveform that provides the range to the surface. Multiple methods exist to execute this procedure based on different assumptions about the interaction of radar energy and the surface.

\section{TRACKING SURFACE HEIGHT FROM CS-2 WAVEFORMS}

We begin our analysis with a description of the respective retracking procedures for each method. The retracking procedure aims to provide the best estimate of range between the satellite center of mass and the dominant backscattering horizon on the Earth's surface. This is achieved by interrogating ESA's baseline B Level 1B (SIR_SIN_L1) waveforms. It results in geolocated surface heights $\left(h^{*}\right)$ which are referenced to the World Geodetic System 1984 (WGS84) ellipsoid after subtracting retracked range from the satellite's altitude.

\subsection{European Space Agency Level 2 data product (ESAL2)}

We utilize ESA baseline B Level 2 SIN mode (SIR_SIN_L2) data which have already undergone a retracking procedure (Bouzinac, 2013). Using SIR_SIN_L1 the ESA processor applies a model fit to determine heights from waveforms fitted to the model echo shape (Wingham and others, 2004, 2006). The ESA waveform retracker is described as a 'customer furnished item' in the CryoSat Product Handbook (Bouzinac, 2013), but no further information is provided by ESA at the time of this publication. Using SIR_SIN_L1 and SIR_SIN_L2 data in unison from CS-2 data within our study area, the retracking point is shown to vary on the leading edge over a range of $40-70 \%$ of peak power (Fig. 2). Using phase information, a correction for off-nadir scattering is also applied in this product. With the available literature we are unable to conclude with confidence which surface (air/ snow or snow/ice) is expected to dominate the backscatter, or what assumptions are made in the model.

\subsection{Waveform Fitting procedure data product $(W f F)$}

Kurtz and others (2014) provide an overview of this product. Surface height is estimated by fitting a physical model to the SIR_SIN_L1 waveforms. The model parameters include the surface roughness, which is assumed to be Gaussian, and the variation of the backscatter with incidence angle.

Dependent upon the parameters described in Kurtz and others (2014), WfF establishes its retracking point at $\sim 50$ $90 \%$ (Fig. 2) of peak power on the leading edge for nonspecular returns and assumes that the dominant backscattering surface is the ice/snow interface. For specular returns, the model converges to the shape of the compressed transmit pulse and the retracking point is near the point of peak power, but can also be beyond the leading edge due to the finite sampling resolution of the waveform.

For the SIN mode data used in this product, the phase information is used to determine the angle to the point of closest arrival determined by the retracking point. A correction for the retracked height, due to off-nadir scattering, is determined and applied from the phase information using the procedure described by Armitage and Davidson (2014).

\subsection{Threshold-First-Maximum-Retracker-Algorithm 40 (TFMRA40)}

This product is based on SIR_SIN_L1 waveforms, but phase information from the returning echo is discarded. The range of the main scattering horizon is obtained by applying a Threshold-First-Maximum retracker to the waveforms. In this study we use a threshold of $40 \%$. The processing follows Ricker and others (2014) by:

1. Oversampling of the original waveform by a factor of 10 using linear interpolation. 
2. Smoothing of the oversampled waveform by applying a running mean with a width of ten range bins to reduce noise.

3. Determination of the first maximum by the derivative of the interpolated curve.

4. Retrieval of the ellipsoidal elevations by tracking the leading edge of the first maximum at $40 \%$ of the peak power (as in Fig. 2).

The main scattering horizon is assumed to be close to the surface, whether this is the air/snow interface or, in the absence of snow cover, the ice/air interface.

\subsection{Tracking of sea surface height}

The sea surface state at the time of the satellite overpass can alter the shape of the returning waveform. Over leads, given their small fetch, the surface is typically smooth. This provides a uniform surface with a characteristic specular waveform response, an ideal surface for both discrimination of water from sea ice and the use of consistent techniques for tracking the sea surface. However, as the size of the open-water area being referenced is increased so is its susceptibility to wind. This is clearly evident over the polynya area in McMurdo Sound, which does not exhibit the typical specular waveform expected from a lead. This is the first of three issues related to the identification of sea surface height ( $\mathrm{SSH}$ ) noted in this study and is described in more detail below. These areas were observed to hamper the identification of SSH in certain sea conditions. When the significant wave height (SWH) is increased by wind forcing, the slope of the leading edge of the radar waveform is flatter due to increasing off-nadir contributions. In the case of TFMRA4O this influence resulted in insufficient separation of fast-ice elevation retrievals from sea surface retrievals (i.e. $\mathrm{SSH}$ was too high relative to the sea-ice surface). Such an influence was not observed on the ESAL2 or WfF techniques that retrack 'higher' on the leading edge and attempt to account for physical differences in surface roughness and incidence angle backscatter variations. This emphasizes the need for the inclusion of an additional surface type to the TFMRA4O procedure. The surface type polynya has been added to the original three, ocean, lead and sea ice (Ricker and others, 2014), to accurately record SSH for the openwater area in McMurdo Sound. Over surfaces flagged as polynya the surface is tracked at $60 \%$, as opposed to $40 \%$ over leads and sea ice. This increase in the retracking threshold accommodates for the flatter leading edge forced by a higher $\mathrm{SWH}$. This amendment improved agreement between TFRMA4O freeboard retrievals and in situ measured freeboard data.

Secondly, the occurrence of 'mixed' surface types within the CS-2 footprint produces noisy waveforms. Regions in which larger open-water areas are intertwined with sea-ice floes and smaller open-water areas, more representative of leads, caused complications with the retracking procedure. These conditions were more prevalent in 2011, when ice floe conditions were more variable in the regions classified as open-water areas. The WfF procedure was influenced by this, which led to SSH retrievals being too low. Slight amendments were applied to attempt to discard noisy waveforms that were causing a delay in range. These amendments, which attempted to remove noisy waveforms by assessing the occurrence of early peaks in power before maximum power, and altering the initial guess of the power to be retracked, resulted in negligible improvements. Further improvement of this procedure is a current research focus.

Thirdly, as the leading edge is not necessarily affected over its entire height in the same manner, this can result in the influence of sea conditions being variable between retrackers that are operating at different positions on the leading edge (Fig. 2). This introduces an inter-retracker bias given the same sea surface conditions. The quantification of these errors is not within the scope of this study given our inability to confidently establish sea surface conditions at the time of data acquisition. Although we are not able to fully resolve all the issues discussed in this section we include them here to provide context for the discussions which follow.

\section{SUPERVISED FREEBOARD RETRIEVAL PROCEDURE}

The retrieval of sea-ice freeboard from radar altimetry requires multiple processing steps. These steps remove spurious influences on the height profile, revealing desired variations driven by freeboard.

At this stage the main uncertainties in the CS-2 freeboard retrieval are driven by:

1. The ability of an algorithm to distinguish between water and sea ice and therefore accurately establish $\mathrm{SSH}$.

2. The availability and accuracy of snow depth information.

3. The limited understanding of the reflected waveform as a function of surface and volume scattering.

Here we minimize the uncertainty under point 1 with the use of MODIS optical imagery by undertaking a supervised identification of the sea surface, establishing a more accurate $\mathrm{SSH}$. We greatly reduce the uncertainty from point 2 with available in situ snow depth/density information. We use these additional data sources, and retrieve a supervised freeboard $\left(\mathrm{Fb}_{\text {sup }}\right)$ for six $\mathrm{CS}-2$ tracks, three from each year 2011 and 2013, for the period mid-November to early December (Fig. 3). This places the in situ measurements in near temporal coincidence with the CS-2 data which were acquired between 21 November and 4 December. The uncertainty introduced by point 3 is expanded upon in Section 6.

We begin our analysis using $h^{*}$ estimated for each technique in Section 3, which is first corrected for varying influences on the transmitted radar wave as it propagates through the atmosphere $\left(c r_{t}\right)$ : dry tropospheric, wet tropospheric and ionospheric corrections (Bouzinac, 2013). The ellipsoidal height is then reduced to a quasi-orthometric height $(h)$ after subtracting geoid height $(N)$ provided by the Earth Gravitational Model 2008 (EGM2008). This approximates mean sea level (MSL). To construct a SSH from this, further information is needed to quantify the sea surface height anomaly, which is the sum of the varying influences of tides $(t)$ and atmospheric pressure and wind (i). No corrections are applied for $t$ at this stage, as the tidal gradient was found to be negligible over the spatial area in the supervised assessment. This was determined through the use of global navigation satellite systems (GNSS) stations deployed on fast ice in McMurdo Sound which showed no tidal gradient across the assessed distances (Price and 
Table 1. Mean freeboard values, standard deviations and sample sizes $(n)$ derived by each retracker by the supervised procedure in austral spring (November and December) 2011 and 2013 and comparison to interpolated in situ mean ice $\left(F_{\mathrm{i}}\right)$ and snow freeboards $\left(F_{\mathrm{s}}\right)$. The satellite tracks from which each $\mathrm{Fb}_{\text {sup }}$ mean is derived are displayed in blue in Figure 3

$\begin{array}{ccc}\text { Retracker } & \text { Spring } 2011 & \text { Spring } 2013 \\ \mathrm{Fb}_{\text {sup }} n=148 & \mathrm{Fb}_{\text {sup }} n=163 \\ \mathrm{~m} & \mathrm{~m}\end{array}$

\begin{tabular}{lll}
\hline $\mathrm{Fb}_{\mathrm{i}}$ & $0.22 \pm 0.07$ & \\
$\mathrm{Fb}_{\mathrm{s}}$ & $0.33 \pm 0.01$ & $0.21 \pm 0.04$ \\
$E S A L 2 \mathrm{Fb}_{\text {sup }}$ & $0.29 \pm 0.14$ & $0.26 \pm 0.04$ \\
WfF Fb & $0.36 \pm 0.13$ & $0.17 \pm 0.13$ \\
TFMRA4O Fb & $0.36 \pm 0.15$ & $0.29 \pm 0.11$ \\
\hline
\end{tabular}

others, 2014). Given the $\sim 50 \mathrm{~km}$ distance, we also expect the influence of $i$ to be negligible. We therefore arrive at $h$ with

$$
h=\left(h^{*}+c r_{t}\right)-N
$$

Using MODIS imagery we identify open-water areas along each CS-2 track and manually prescribe surface types of water or sea ice to each $h$ value. The construction of SSH requires the removal of surface height outliers over the water surface type. The mean is largely biased by such outliers, so, in this case, where we are confident open water dominates, we use the median to establish the supervised $\mathrm{SSH}\left(\mathrm{SSH}_{\text {sup }}\right)$. We sample $\sim 25 \mathrm{~km}$ sections along track, which provides $\sim 100$ individual $h$ values from which to construct $\mathrm{SSH}_{\text {sup. }}$. Radar freeboard $\left(\mathrm{Fb}_{\text {radar }}\right)$ is then derived by

$$
\mathrm{Fb}_{\text {radar }}=h-\mathrm{SSH}_{\text {sup }}
$$

Given the assumptions about each retracker with regard to snow penetration, we follow Kurtz and others (2014) and freeboard is then derived with the addition of a correction for the speed of light in snow. This correction $\left(h_{\mathrm{c}}\right)$ over seaice areas is given by

$$
h_{\mathrm{c}}=s_{h}\left(1-\frac{C_{\text {snow }}}{c}\right)
$$

where $s_{h}$ is the snow depth, $c$ the speed of light in a vacuum, and $c_{\text {snow }}$ the speed of light in the snowpack following Tiuri and others (1984) parameterized as

$$
c_{\text {snow }}=\frac{c}{\sqrt{1+1.7 \rho_{\mathrm{s}}+0.7 \rho_{\mathrm{s}}^{2}}}
$$

where $\rho_{\mathrm{s}}$ is the snow density $\left(\mathrm{g} \mathrm{cm}^{-3}\right)$ measured as $0.385 \mathrm{~g} \mathrm{~cm}^{-3}$ in McMurdo Sound (Price and others, 2014). This value was also measured as the mean snow density from in situ measurements in 2013. $s_{h}$ is provided by the spatial interpolation of in situ snow depth measurements. With regard to snowpack penetration by the incident radar wave we assume full penetration for ESAL2 and WfF and no penetration for TFMRA40. The reduction of $c$ in the snow cover results in an increased range estimate from satellite to surface. This will force a negative bias in the resultant freeboard if uncorrected; we therefore arrive at $\mathrm{Fb}_{\text {sup }}$ for each respective retracker under the manual assessment over fast ice with

$$
\mathrm{Fb}_{\text {sup }}=\mathrm{Fb}_{\text {radar }}+h_{\mathrm{c}}
$$

We treat $\mathrm{Fb}_{\text {sup }}$ outliers by removing any retrieval that deviates by $>3$ standard deviations from the mean over the sea-ice area. Finally, we ensure datasets are comparable with the manual removal of $\mathrm{Fb}_{\text {sup }}$ values that are not available for all three products.

\subsection{Supervised freeboard retrieval results}

In this subsection, we provide results from the supervised analysis of CS-2 derived freeboards from each retracker. We compare these results to in situ freeboard measurements and use this in combination with complementary field and satellite data to relate the effect of surface conditions on the resultant $\mathrm{Fb}_{\text {sup }}$ values. In situ ice freeboard $\left(F_{\mathrm{i}}\right)$ and snow freeboard $\left(F_{\mathrm{s}}\right)$ are provided from the interpolation of in situ measurements and extracted to be spatially coincident with each individual CS-2 $\mathrm{Fb}_{\text {sup }}$ retrieval (the tracks of which are shown in Fig. 3). This step was undertaken to provide a better spatial comparison between in situ measurements and CS-2. The mean values of the interpolated points extracted at each $\mathrm{Fb}_{\text {sup }}$ retrieval agree to within $0.01 \mathrm{~m}$ of the in situ mean values. The variability introduced by the interpolation is largest with regard to $\mathrm{Fb}_{\mathrm{s}}$ driven by variations in $s_{h}$. Leaveone-out cross-validation indicates that a maximum deviation of $0.05 \mathrm{~m}$ can be expected (Price and others, 2014). $\mathrm{Fb}_{\text {sup }}$ which are the mean values of the three CS-2 tracks in each year are shown with in situ means in Table 1 . The retracking techniques produce $\mathrm{Fb}_{\text {sup }}$ mean values ranging from 0.17 to $0.36 \mathrm{~m}$, which are in line with the range of in situ measured freeboards in McMurdo Sound of 0.21$0.33 \mathrm{~m}$. All retrackers provide higher $\mathrm{Fb}_{\text {sup }}$ estimates in 2011 than in 2013 when the snow was deeper. $2013 \mathrm{Fb}_{\text {sup }}$ values for each technique are in agreement with what is expected given the assumptions of the described retrackers (see Fig. 2 and difference in range), WfF the lowest and TFMRA4O the highest. WfF shows closer agreement with $F_{\mathrm{i}}$, while TFMRA40 freeboards are closer to $F_{\mathrm{s}}$. ESAL2 $\mathrm{Fb}_{\text {sup }}$ is established between $F_{\mathrm{i}}$ and $F_{\mathrm{s}}$. Therefore, the trivial relationship between differences in retracked range and resultant freeboard values is maintained in 2013. The comparison is complicated in 2011 with regard to $W f F$, as its $\mathrm{Fb}_{\text {sup }}$ value is $0.19 \mathrm{~m}$ higher than in 2013 , with only a $0.01 \mathrm{~m}$ change in $F_{\mathrm{i}}$ recorded in situ. The cause of this discrepancy is unclear. It is likely that interference with $\mathrm{SSH}_{\text {sup }}$ establishment, as alluded to in Section 3.4, played a role in the high freeboard value for $W f F$, but we also need to consider the influence of the snow cover. The full snow-cover penetration assumption of the WfF method may not be fulfilled given a smooth snow cover can be an effective scatterer of the incident radar energy. When the echo power from the snow/ice interface and that from the air/snow interface have a similar magnitude, a positive freeboard bias may be introduced (Kurtz and others, 2014; Kwok, 2014). This bias is estimated to reach a maximum of $0.04 \mathrm{~m}$ for homogeneous snow conditions (Kurtz and others, 2014). It is likely to have played a more significant role here due to snow stratification and wind crusts at the surface. From the limited information about the retracking procedure for ESAL2 we would expect to see a similar relationship. Such a relationship is observed, with ESAL2 $\mathrm{Fb}_{\text {sup }} 0.05 \mathrm{~m}$ higher in 2011 than in 2013.

To provide further insight into the influence of snow cover and ice conditions on the radar signal, we show $\mathrm{Fb}_{\text {sup }}$ along a coincident in situ validation line on 27 November 2013 (Fig. 4). The validation measurements along this line were temporally coincident to within 3 hours of the CS-2 overpass. It should be noted that due to a satellite orbit 


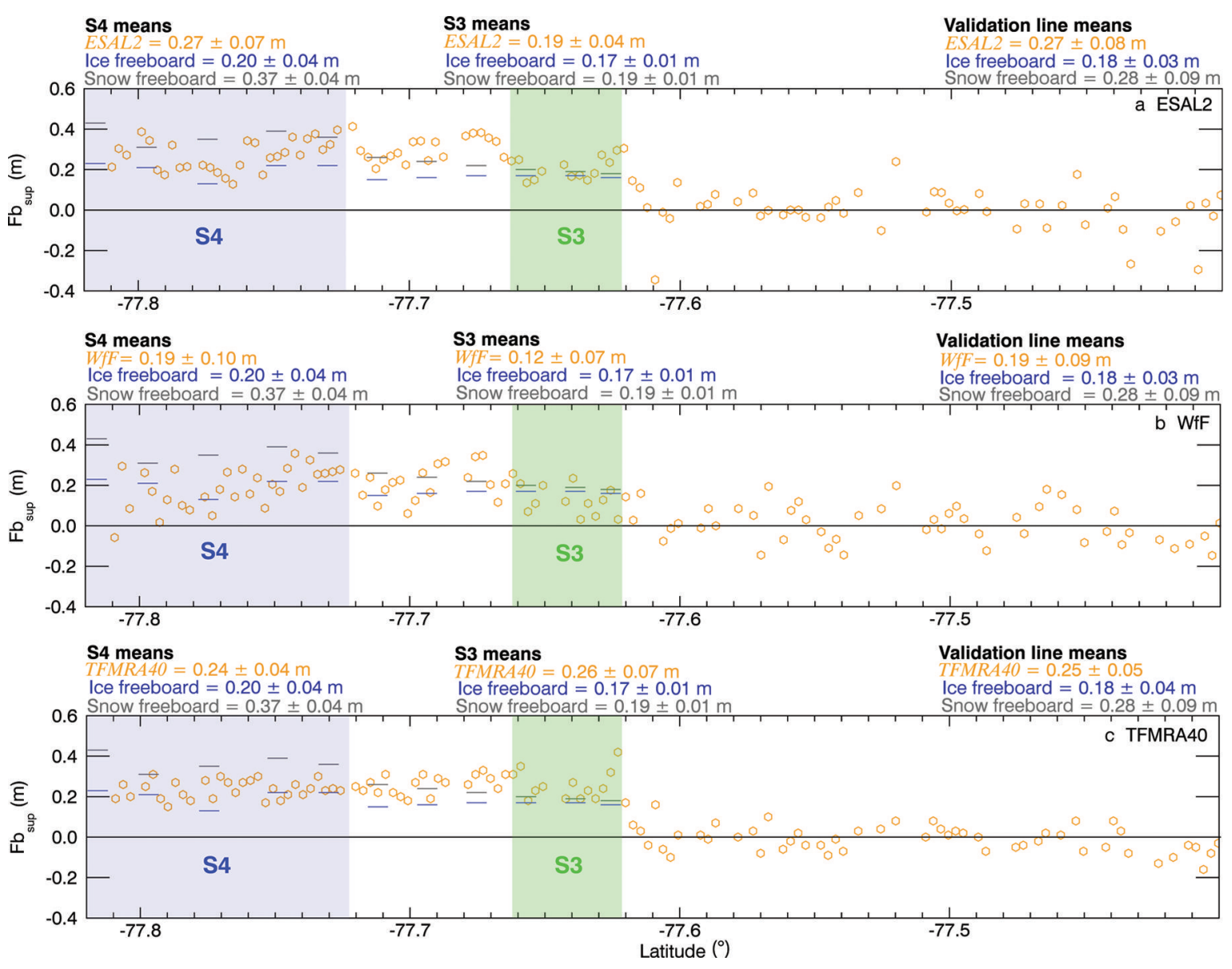

Fig. 4. Comparison of each method along a validation line coincident with a CryoSat-2 overpass on 27 November 2013 for (a) ESAL2, (b) WfF and (c) TFMRA40. In situ measured ice and snow freeboards are shown as blue and grey horizontal lines respectively. Segments 3 (S3) and 4 (S4) in Figure 5 are also shown. Sea surface height was identified using the supervised procedure. The CryoSat- 2 height profile begins in the north over open water and progresses south over the fast-ice edge at the beginning of segment 3 . The freeboard retrievals for each respective retracker are displayed as orange circles, and the validation line statistics describe the sea-ice area only. S3 and S4 means are also displayed for each technique, along with the ice freeboard and snow freeboard measured in situ.

maneuver the validation line was $\sim 1 \mathrm{~km}$ east of the CS-2 ground track. Visually we observed no significant changes to the characterized sea-ice surface conditions or snow depth over this distance and therefore find the in situ and CS-2 datasets comparable. The surface conditions on the sea ice varied along the validation line from north to south. Clear differences in $\mathrm{Fb}_{\text {sup }}$ are displayed between the techniques. Mean $\mathrm{Fb}_{\text {sup }}$ for WfF shows good agreement with $F_{\mathrm{i}}$. ESAL2 mean $\mathrm{Fb}_{\text {sup }}$ is in better agreement with $F_{\mathrm{s}}$, but the response of the height retrievals to surface conditions follows a similar pattern to that observed for WfF. TFMRA4O has a very consistent $\mathrm{Fb}_{\text {sup }}$ profile which exhibits minimal response to changing surface conditions, producing values that closely agree with $F_{\mathrm{s}}$ across the whole profile. We are able to assess the response of each of the retracking techniques to the presence of a homogeneous section of dry snow in segment 4 (Fig. 4). For all techniques, Fb $b_{\text {sup }}$ appears to track an interface which is in good agreement with measured in situ $F_{\mathrm{i}}$ over segment 4. ESAL2 and WfF record the in situ measured decrease in $\mathrm{Fb}_{\mathrm{i}}$ in the central part of the segment. Further in support of WfF assumptions, its mean $\mathrm{Fb}_{\text {sup }}$ value agrees to within $0.01 \mathrm{~m}$ of in situ measured $F_{\mathrm{i}}$ with no positive bias as CS-2 passes over this area of relatively homogeneous snow cover (segment 4: mean WfF $\mathrm{Fb}_{\text {sup }}=0.19 \mathrm{~m}$, in situ $F_{\mathrm{i}}=0.20 \mathrm{~m}$, in situ $F_{\mathrm{s}}=$ $0.37 \mathrm{~m}$ ). However, for the $2011 \mathrm{WfF}$ freeboard, measured when the snow cover was smoother and more layered in comparison to segment 4 in 2013, the mean WfF Fb sup value is $0.36 \mathrm{~m}, 0.14 \mathrm{~m}$ higher than $F_{\mathrm{i}}$ (Table 1). Both ESAL2 and WfF clearly exhibit a large variability in freeboard retrievals over sea ice in response to either snow or ice conditions.

We attempt to separate the influences of snow and seaice conditions using near-coincident TerraSAR-X (X-band) imagery, in situ measurements, and observations. We provide four segments in McMurdo Sound in 2013 over which sea-ice geometric roughness (GR) and radar roughness (RR) varied. Considering the similar wavelengths in $X$ band $(\sim 0.03 \mathrm{~m})$ and $\mathrm{Ku}$ band $(\sim 0.02 \mathrm{~m})$, and also assuming the incidence angle dependence of backscattering properties is dominated by surface scattering, a near-inverse relationship between backscattered power between TerraSAR-X (40 incidence angle) and CS-2 (normal incidence) can be expected (Ulaby and others, 1982). In the TerraSAR$X$ image the relatively bright areas on level sea ice (bounded by a white dotted line in Fig. 5a) are rough with respect to the radar wavelength, and the dark areas are smooth. For the sea-ice area, we assess the differences in CS-2 waveforms that have been averaged and stacked to represent these different segments. The numbers of waveforms averaged to create each representative waveform were between 15 and 28. We identify an area of high GR (segment 1: FY ice that has likely been deformed by storm activity) and low GR 

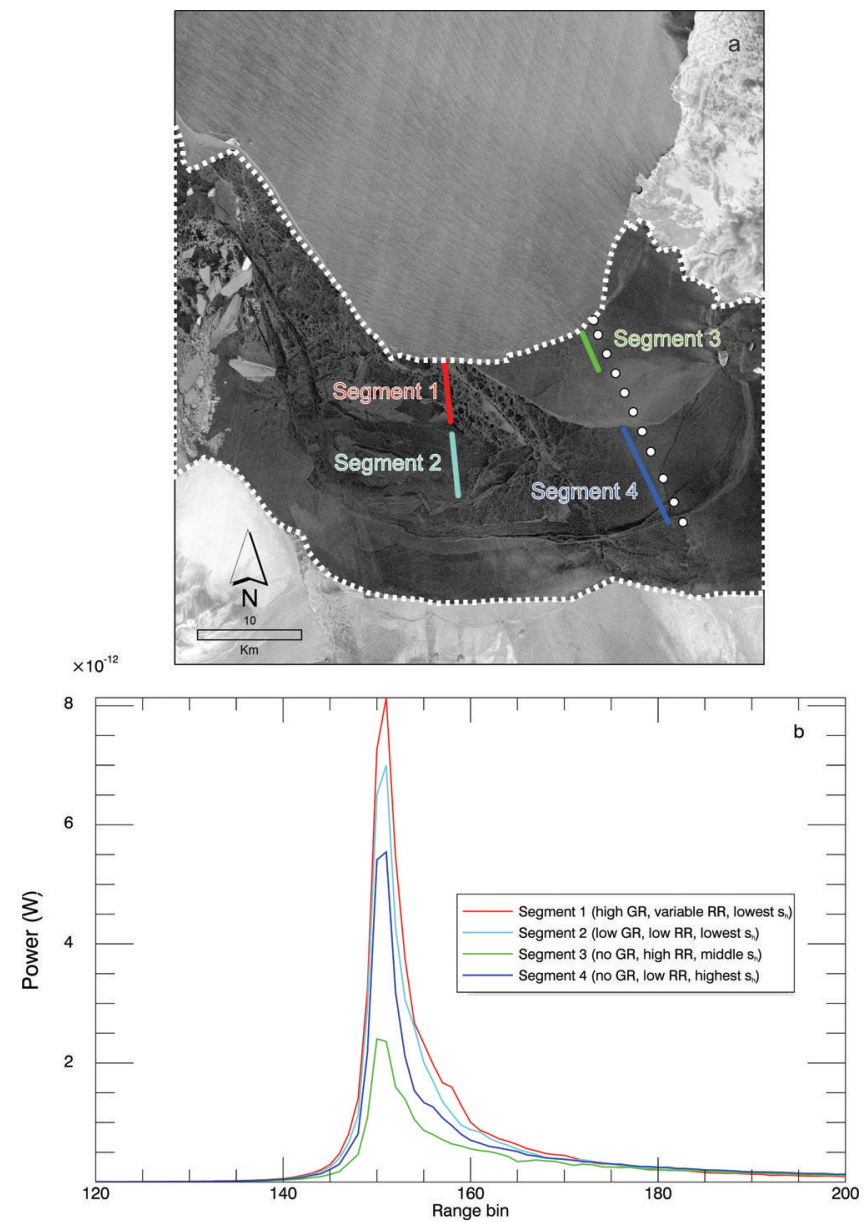

Fig. 5. (a) Segments 1-4 over the first-year sea-ice area (bounded by white dotted line) overlaid upon a TerraSAR-X radar image from 28 November 2013. TerraSAR-X image (courtesy DLR (German Aerospace Center)). (b) Mean waveforms from these segments plotted as power for multiple sea-ice surface conditions with variable geometric roughness $(\mathrm{GR})$, radar roughness $(\mathrm{RR})$ and snow depth $\left(s_{h}\right)$.

(segment 2: older FY ice which was less deformed) over the FY fast-ice area. These were established primarily from field observations, with the TerraSAR-X image as support. Segment 1 (high GR, variable RR, lowest $s_{h}$ ) causes the largest power return, closely followed by segment 2 (low GR, low RR, lowest $s_{h}$ ). It is clear that other variables also influence the signal return, which is evident from comparison of segments 3 and 4 . Segment 3 has the lowest power return of the assessed waveforms and exhibits high radar backscatter in the TerraSAR-X image. This indicates that RR is high. These observations are supportive of the fact that $R R$ is the dominant influence on the power returned to the satellite and that GR is playing a secondary role. It is difficult to attribute the influence of volume scattering from snow, as no areas with the same RR are available with large differences in snow depth.

In an attempt to assess the influence of snow depth, we look at two tracks in 2011 that exhibited a larger difference in snow depth for which we expect RR to be less variable. For these example tracks, the waveforms retrieved over snow (mean depth $0.20 \mathrm{~m}$ ) and those retrieved over reduced snow (mean depth $0.07 \mathrm{~m}$ ) are displayed in Figure 6 with the retracking points for each technique. These waveforms are the mean normalized echo power of $\sim 50$ waveforms and are aligned by peak power to achieve comparativeness
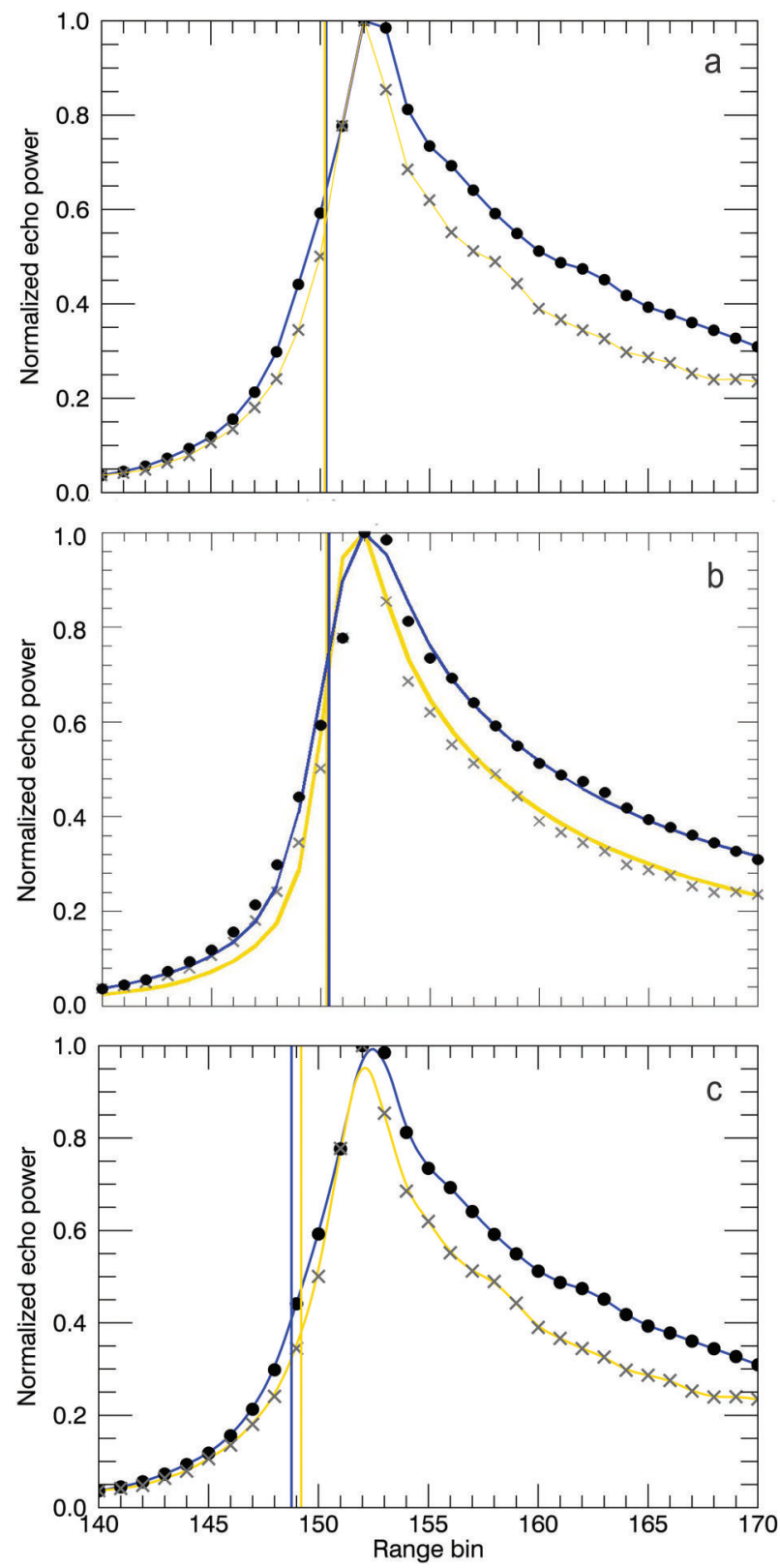

Fig. 6. Mean waveform examples for sea ice in 2011 with significant snow cover (circles and blue fits) and minimal snow cover (crosses and orange fits). The area with significant snow cover had a mean snow depth of $0.20 \mathrm{~m}$ with consistent coverage. Over the minimal area a mean snow depth of $0.07 \mathrm{~m}$ was measured with a patchy distribution. (a) The retracking points for ESAL2 with linear fits between each bin; (b) the retracking points for WfF with respective model fits; and (c) the retracking points for TFMRA4O with interpolated curves.

between each technique. The mean retracking point for each waveform for each technique is also displayed. It should be noted here that comparison of their absolute range differences cannot be inferred from the available information, only the inter-example variation in the waveform shape. It is shown that in the presence of a snow cover of $\sim 0.20 \mathrm{~m}$ the slope of the leading edge becomes shallower, and that the power of the trailing edge is increased along with the overall width of the waveform. This finding is comparable to results of simulations of CS-2 waveform responses to increasing snow cover provided by Kwok (2014). 


\section{AUTOMATIC FREEBOARD RETRIEVAL PROCEDURE}

In this section we develop automatic freeboard retrieval procedures without the prerequisite for coincident satellite imagery for the establishment of SSH. The automatic differentiation of sea ice and water is a fundamental requirement for large-scale altimetric sea-ice freeboard retrieval. Automated methods generally fall into two categories, the first relying on the use of information received in the returning signal from the surface and the second on mathematical generalizations that approximate expected surface conditions, or, a combination of the two. In the case of CS-2, methods currently presented in the literature (Laxon and others, 2013; Kurtz and others, 2014; Ricker and others, 2014) fall into the first category, following similar investigative procedures initially demonstrated by Peacock and Laxon (2004). These contemporary methods use the pulse peakiness and stack standard deviation, among other parameters, to differentiate between radar returns from small open-water leads in the sea-ice cover and sea-ice floes. In the second category, the expected amount of water along-track is given a value, and the heights of this lowest percentage are averaged for a certain segment of track, giving a sea surface height (Zwally and others, 2008; Price and others, 2013). This approach, commonly termed along-track filtering, is yet to be examined in the literature with respect to $\mathrm{CS}-2$. The three automatic retrieval procedures used for each retracking method are described in the following subsections.

Following from $h$ established in Section 4, all data undergo the same additional corrections to produce comparable datasets. $h$ is further corrected for $t$ and $i$ to give $H$ :

$$
H=h+t+i
$$

The influence of $i$ is accounted for using a dynamic atmosphere correction and compensates for the influence of barometric pressure and winds on the sea surface. $t$ is the sum of corrections for ocean tide, long-period equilibrium tide, ocean loading tide, solid earth tide and the geocentric pole tide. Further details on the corrections applied for $t$ and $i$ are given in Bouzinac (2013). These additional corrections accommodate for the larger geographical region under investigation in the automatic procedure (Fig. 3) over which tidal and atmospheric effects will be influential on the 'flattening' of the height profile. Each method then produces its own automatic $\mathrm{SSH}\left(\mathrm{SSH}_{\text {auto }}\right)$ to provide $\mathrm{Fb}_{\text {auto }}$ as

$$
\mathrm{Fb}_{\text {auto }}=\mathrm{H}-\mathrm{SSH}_{\text {auto }}
$$

No adequate snow depth information is available for the two annual periods assessed by the automatic procedure, so no correction is applied for $h_{c}$. The procedures for attaining $\mathrm{SSH}_{\text {auto }}$ for each technique and other relevant amendments are described in the following subsections.

\subsection{ESAL2 automatic SSH identification}

Measurement quality flags provided in the CS-2 Level 2 record structure were used to improve the quality of the dataset. $H$ values are discarded if the following parameters in the product are flagged as poor: block degraded, orbit error, orbit discontinuity, height error, calibration caveat, backscatter error, peakiness error, SIN cross-track angle error, SIN receive channel 1 error, SIN receive channel 2 error, mispointing error and delta time error which are given in Bouzinac (2013). In SIN mode, the off-nadir location of the height retrieval can be determined from phase information of the dominant scattering in the power echo, which over seaice areas can be significantly off-nadir (Armitage and Davidson, 2014). This ability prevents underestimations of ocean elevation as a result of 'snagging' from leads located off-nadir, providing a reduction in noise over height profiles. According to the across-track offset computed from the phase difference, open water and level sea-ice areas also produce echoes geolocated off-nadir. From assessment of $\sim 800$ separate elevation retrievals over open water in McMurdo Sound from two tracks in 2013, identified by comparison with near-coincident MODIS imagery, the mean deviation from nadir was $270 \pm 70 \mathrm{~m}$. We apply a removal threshold of $\pm 750 \mathrm{~m}$ from nadir simply to limit information to the expected nadir footprint area, maintaining comparativeness to the TFMRA40 method and to in situ measurements.

To remove height outliers we apply a vertical threshold of \pm 2 standard deviations of the mean to each track. Heights outside this threshold are discarded.

We use the Level 2 parameter peakiness $(P)$ to differentiate between three surface types: open water, leads and fast ice. $P$ is suggestive of how sharply peaked the returning waveform is, and is defined as the ratio of the highest bin value to the mean of all bins above the retracking point (Bouzinac, 2013). $P$ ranges between 0 and 120 in our investigation area (Fig. 7). High $P$ values are indicative of leads, which are geometrically of similar size to the radar footprint and typically have specular surfaces. Low $P$ values are indicative of openwater areas that are geometrically larger than the radar footprint and are typically diffuse surfaces. Fast-ice $P$ values are between these two extremes but are affected by sea-ice surface conditions. We establish thresholds for these surface types after comparison of $P$ values over certain surface types in the study region as indicated by MODIS and TerraSAR-X imagery and knowledge of the sea-ice regime. $P$ has a large standard deviation even when a certain surface type is completely isolated, indicating it is highly sensitive to small changes in surface conditions.

First we assessed the $P$ threshold for leads. It is very challenging to constrain such a value, due to the difficulty of achieving coincidence between CS-2 measurements and satellite imagery. Therefore, we investigated $P$ values in March when sea ice in McMurdo Sound starts to freeze and the surface is dominated by developing ice floes. At this time, leads are abundant and we take the upper quartile of $P$ values as representative of the leads surface type $(P>90)$ for both years.

The two remaining surface types require further scrutiny due to overlaps in their $P$ distributions. McMurdo Sound was assessed in February 2013 when it was dominated by open water. In both 2011 and 2013 the majority (>95\%) of $P$ values were $<15$. However, in 2011 the surface types open water and fast ice overlapped, whereas in 2013 a clear separation is achievable (Fig. 7). This is a result of fast-ice surface conditions differing in 2011 that lowered values in the $P$ distribution. We are unable to fully establish the cause of this change. The pulse shape and, thus, $P$ are largely determined by variation of backscatter with incidence angle (Wingham and others, 2006). This is related to RR, and, given the differing conditions over the fast ice between the two years, a change in RR at the dominant backscattering surface was likely the cause. In 2013 it is possible to clearly differentiate and establish open water as $P<15$ and fast ice as $15<P<90$. In 2011 we lowered the threshold for open 

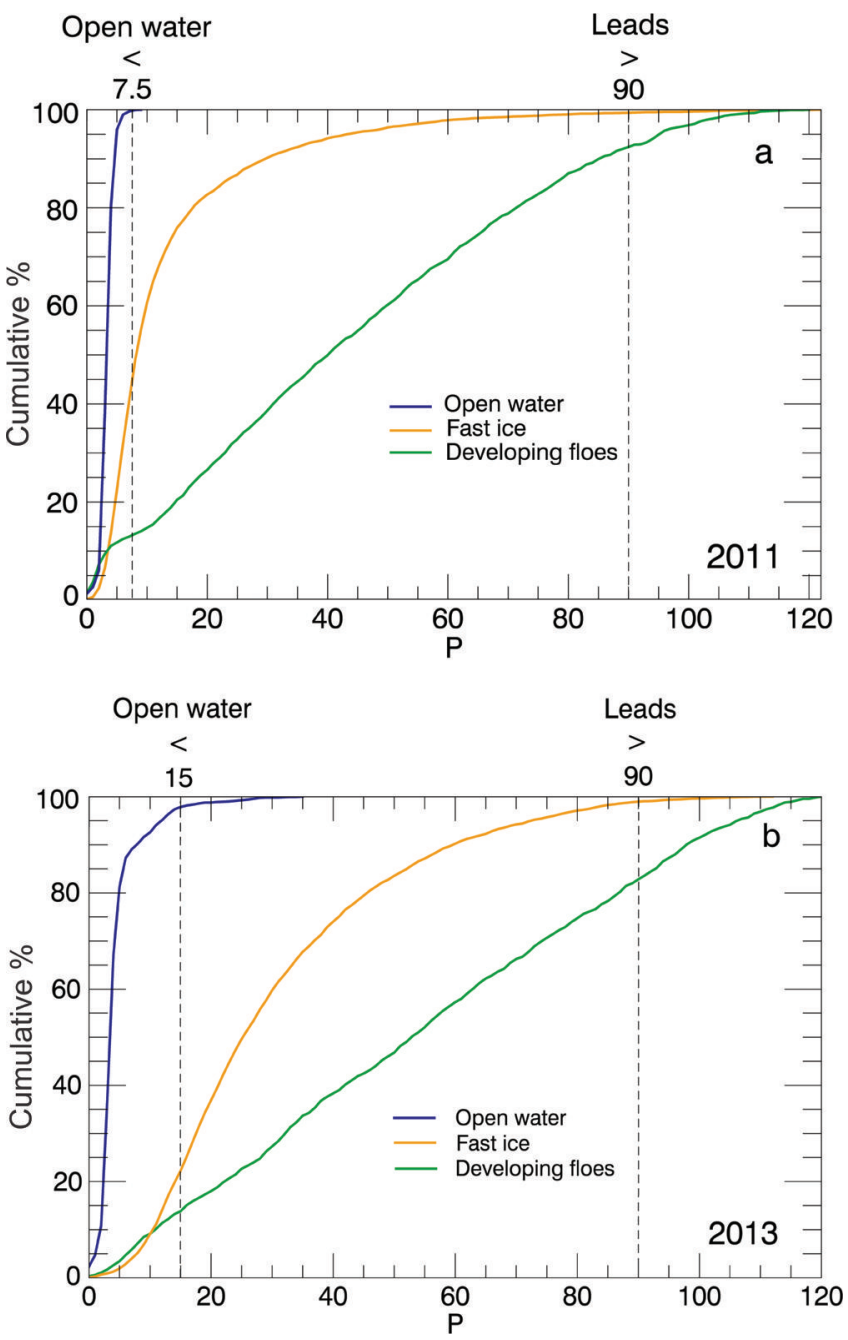

Fig. 7. Surface type discrimination as indicated by Level 2 parameter peakiness $(P)$ displayed as a cumulative percentage. Surface types, open water, fast ice and developing floes are displayed for 2011 (a) and 2013 (b). In 2011, surface conditions made the discrimination of open water and fast ice more difficult. This resulted in a change in the thresholds between the years. The expected inclusion of sea ice in the open-water surface type is indicated by the percentage overlaps.

water to $P<7.5$ to reduce the amount of fast ice potentially included in the expected open-water retrievals. 2011 fast ice is therefore given thresholds of $5<P<90$. We appreciate these thresholds for open water and fast ice overlap, but if a higher bound is taken for the lower limit of $P$ for fast ice in $2011, \sim 60 \%$ of height retrievals identified as fast ice will be discarded. The fast-ice $P$ distributions were established from assessment of the fast-ice area. The sea-ice growth season in McMurdo Sound begins in March, but fast ice does not become fully established for some time. We are confident that fast ice is fully established by August and derive a $P$ value for this surface type by masking fast-ice area from August to December. We assume the fast-ice area is also representative of $P$ values for ice floes in McMurdo Sound. Finally, due to the discussed overlaps of open water and fast ice (Fig. 7), and potential inclusion of sea ice in expected open-water retrievals, it is necessary to filter $H$ values with regard to their heights. This approach is altered for each year to account for the expected inclusion of ice in the openwater retrievals (Fig. 7; 40\% in 2011 and $20 \%$ in 2013). We calculate the means of the lowest $60 \%$ of $H$ values in 2011 and $80 \%$ in 2013 that meet the open-water and lead criteria and establish $\mathrm{SSH}_{\text {auto }}$ for each track from this.

\subsection{WfF automatic SSH identification}

We attain $\mathrm{SSH}_{\text {auto }}$ by using a similar parameter to ESA Level $2 P$, the pulse peakiness (PP) as described by Armitage and Davidson (2014). The assigned values for the discrimination of each surface type were chosen after comparison of PP values over surface types in the study area using the same method as described for ESAL2 in Section 5.1. We flag leads as $\mathrm{PP}>0.30$ and open water as $\mathrm{PP}<0.05$. Sea ice is classified as $0.08<\mathrm{PP}<0.30$. Overlaps of sea-ice and open-water surface types were noted as in Section 5.1. To remove this height bias from inclusion of sea ice, we establish $\mathrm{SSH}_{\text {auto }}$ from the mean of the lowest $60 \%$ and $80 \%$ of elevations flagged as leads of open water in 2011 and 2013 respectively. Phase information is also used in this product in the same manner as ESAL2. We again remove elevation outliers with application of a vertical threshold of \pm 2 standard deviations of the mean to the track.

\subsection{TFMRA40 automatic SSH identification}

We use the algorithm described in Ricker and others (2014) but amend the procedure, as surface conditions differ in the investigation area from those for which the technique has previously been applied. As mentioned in Section 3.4 we maintain the inclusion of the additional surface type, polynya, and its amended $60 \%$ retracking threshold. The elevations retrieved for both leads and polynyas in close proximity should be of the same mean value to construct a consistent $\mathrm{SSH}_{\text {auto }}$. We compared the elevations of detected leads that were in close proximity to the polynya surface type for several CS-2 tracks and found sufficient agreement using a $60 \%$ and $40 \%$ threshold for each surface type in conjunction. Track sections with a significantly inaccurate $\mathrm{SSH}_{\text {auto, }}$ as a consequence of sparse lead/open-water coverage, have been discarded.

\subsection{Automatic results}

The application of the three retracking techniques produced Fb auto datasets for McMurdo Sound for 2011 and 2013 (Table 2). All techniques show a decrease in freeboard in McMurdo Sound from 2011 to 2013 over the study area as a whole, and the fast-ice area when assessed alone. The magnitude of this change varies between methods. ESAL2 and TFMRA4O both identify the fast-ice area as having a higher freeboard than the mean of the entire study area. WfF does not show such a relationship, with fast-ice mean $\mathrm{Fb}_{\text {auto }}$ being $0.01 \mathrm{~m}$ lower in 2011 and the same value in 2013. A lower mean freeboard is expected for the entire study area, as sea ice in the dynamic MSP area is included. Sea ice in this area is expected to be thinner than the fast ice that has undergone near-continuous and stable growth over winter. This discrepancy may be driven by the identified problems with surface type discrimination. Open-water areas may have been erroneously included as sea ice, lowering the $\mathrm{Fb}_{\text {auto }}$ averages. Clearly apparent are the large standard deviations of the CS-2 data (Table 2).

To investigate the ability of CS-2 further and to minimize the influence of the MSP sea-ice area, we assess the fast-ice area with regard to its seasonal development. The FY fast-ice regime in McMurdo Sound typically breaks out in February, and often in one of every two years (Heine, 1963) leaves McMurdo Sound nearly entirely ice-free. Sea ice begins to 
Table 2. Mean automatic procedure freeboard values and standard deviations derived by each technique for each year for the entire study area and fast ice only (bold). The total number of measurements $(n)$ for each year is also displayed. The spatial distribution of the satellite tracks from which the $\mathrm{Fb}_{\text {auto }}$ means are derived are shown in orange in Figure 3

\begin{tabular}{|c|c|c|}
\hline Retracker & $\begin{array}{c}2011 \\
\mathrm{~m}\end{array}$ & $\begin{array}{c}2013 \\
\mathrm{~m}\end{array}$ \\
\hline ESAL2 $\mathrm{Fb}_{\text {auto }}$ & $\begin{array}{l}0.09 \pm 0.25 \\
\mathbf{0 . 1 1} \pm \mathbf{0 . 2 7} \\
(n=16611)\end{array}$ & $\begin{array}{l}0.08 \pm 0.24 \\
\mathbf{0 . 0 9} \pm \mathbf{0 . 2 6} \\
(n=12884)\end{array}$ \\
\hline WfF $\mathrm{Fb}_{\text {auto }}$ & $\begin{array}{c}0.12 \pm 0.24 \\
\mathbf{0 . 1 1} \pm \mathbf{0 . 2 5} \\
(n=7094)\end{array}$ & $\begin{array}{c}0.10 \pm 0.23 \\
\mathbf{0 . 1 0} \pm \mathbf{0 . 2 2} \\
(n=9439)\end{array}$ \\
\hline TFMRA4O $\mathrm{Fb}_{\text {auto }}$ & $\begin{array}{c}0.16 \pm 0.35 \\
\mathbf{0 . 2 3} \pm \mathbf{0 . 3 6} \\
(n=7532)\end{array}$ & $\begin{array}{c}0.11 \pm 0.38 \\
\mathbf{0 . 1 5} \pm \mathbf{0 . 4 6} \\
(n=8244)\end{array}$ \\
\hline
\end{tabular}

form in March when air temperatures are low enough to initiate freezing as indicated by field studies (Leonard and others, 2006; Purdie and others, 2006) and MODIS imagery. This was also the case in 2011 and 2013. The sea ice develops into a fast-ice cover in a coastal band (Fig. 3) around McMurdo Sound, with fast-ice establishment intermittently interrupted by storm events (as indicated by optical and SAR imagery). Sea-ice growth continues until about mid-December (Jeffries and others, 1993). We use the region of McMurdo Sound that is covered by fast ice at the end of the growth season as a mask for the entire year. We expect to observe a signal in the recorded $\mathrm{Fb}_{\text {auto }}$ datasets indicative of increasing freeboard from March to December. Such findings are displayed in Figure 8, where we clearly see this development using all three retracking techniques. $\mathrm{Fb}_{\text {auto }}$ increases through autumn and winter toward $\mathrm{Fb}_{\mathrm{i}}$ and $\mathrm{Fb}_{\mathrm{s}}$ in situ measurements in spring. We apply a linear trend from the beginning of March to mid-December to capture the sea-ice growth measured by $\mathrm{Fb}_{\text {auto. }}$. Using this trend to compare $\mathrm{Fb}_{\text {auto }}$ results in mid-November ( day 260 in Fig. 8) to the mean of all in situ measurements in each year, we find ESAL2 Fbauto underestimates $\mathrm{Fb}_{\mathrm{i}}$ in both years by $0.04 \mathrm{~m}$. In 2011 WfF $\mathrm{Fb}_{\text {auto }}$ overestimates in situ measured sea-ice freeboard by $0.08 \mathrm{~m}$ and in 2013 underestimates it by $0.02 \mathrm{~m}$. TFMRA40 provides a mean $\mathrm{Fb}_{\text {auto }}$ value of $0.37 \pm 0.22 \mathrm{~m}$ in 2011, $0.04 \mathrm{~m}$ lower than $\mathrm{Fb}_{\mathrm{s}}$. In 2013 TFMRA40 $\mathrm{Fb}_{\text {auto }}$ underestimates $\mathrm{Fb}_{\mathrm{s}}$ by $0.01 \mathrm{~m}$. All techniques also display a decrease in $\mathrm{Fb}_{\text {auto }}$ after reaching their respective maximums in line with the observed breakout of the fast-ice area in late February/early March of each year. Mean values and standard deviations for each month are displayed in Table 3.

We are able to evaluate the performance of the automatic procedures by comparison of the $\mathrm{CS}-2$ mean $\mathrm{Fb}_{\text {sup }}$ over the validation line (Fig. 4) against the $\mathrm{Fb}_{\text {auto }}$ mean over the same track. With the application of a correction for $c$ in snow, $\mathrm{Fb}_{\text {auto }}$ overestimates $\mathrm{Fb}_{\text {sup }}$ by $0.07,0.05$ and $0.01 \mathrm{~m}$ for ESAL2, WfF and TFMRA4O respectively. The overestimation of freeboard by $\mathrm{Fb}_{\text {auto }}$ for ESAL2 and WfF is driven by the applied along-track filtering of $H$. The filtering assumes a percentage inclusion (20\% for 2013) of sea ice within the total sampled area over water along each track. In this case, the open-water area to the north has an ice concentration of zero and therefore $\mathrm{SSH}_{\text {auto }}$ is established too low, and subsequent $\mathrm{Fb}_{\text {auto }}$ is too high. This simple comparison showcases the additional error which can be expected by applying fully automatic methods for the identification of SSH which only generalize expected open-water availability.

\section{DISCUSSION}

We have evaluated the performance of two retracking techniques currently presented in the literature: WfF (Kurtz and others, 2014) and TFMRA40 (Ricker and others, 2014). The first assumes the surface is retracked at $\mathrm{Fb}_{\mathrm{i}}$ and the second near $\mathrm{Fb}_{\mathrm{s}}$. We also use ESAL2, a product for which we have limited information about its retracking procedure and assumptions therein. Here we discuss the extent to which our in situ observations support the assumptions in view of the mean and standard errors of the measured $\mathrm{Fb}_{\text {sup }}$ and $\mathrm{Fb}_{\text {auto }}$ datasets and information provided by the waveform responses to surface conditions.

As expected, the best agreement is found between in situ measurements and CS-2 freeboard retrieval techniques for

Table 3. Mean automatic procedure freeboard values $(\mathrm{m})$, standard deviations and number of measurements (in parentheses) used to derive the statistics for each technique in each year over the fast-ice area. The data are binned into calendar months. The day corresponding approximately to the middle of each calendar month from the start of the analysis (day zero = 1 March) is also displayed

\begin{tabular}{|c|c|c|c|c|c|c|}
\hline \multirow{2}{*}{$\begin{array}{l}\text { Month (day } \\
\text { after } 1 \text { Mar) }\end{array}$} & \multicolumn{3}{|c|}{2011} & \multicolumn{3}{|c|}{2013} \\
\hline & ESAL2 & $W f F$ & TFMRA4O & ESAL2 & $W f F$ & TFMRA4O \\
\hline $\operatorname{Mar}(+15.2)$ & $-0.04 \pm 0.16(494)$ & $0.00 \pm 0.35(232)$ & $0.05 \pm 0.29(105)$ & $-0.01 \pm 0.30$ & $0.01 \pm 0.21(260)$ & $0.05 \pm 0.19(271)$ \\
\hline Apr $(+45.6)$ & $0.02 \pm 0.24(560)$ & $0.13 \pm 0.18(400)$ & $0.03 \pm 0.15$ & $0.03 \pm 0.12(480)$ & $0.08 \pm 0.15$ & $0.16 \pm 0.43(362)$ \\
\hline May (+76) & $0.06 \pm 0.14(537)$ & $0.12 \pm 0.16(296)$ & $0.14 \pm 0.38(526)$ & $0.05 \pm 0.26(623)$ & $0.13 \pm 0.15(508)$ & $0.08 \pm 0.19(238)$ \\
\hline Jun $(+106.4)$ & $0.14 \pm 0.31(400)$ & $0.02 \pm 0.30(246)$ & $0.05 \pm 0.22(204)$ & $0.07 \pm 0.24(543)$ & $0.04 \pm 0.21(409)$ & $0.03 \pm 0.19(267)$ \\
\hline Jul (+136.8) & $0.19 \pm 0.25(859)$ & $0.17 \pm 0.18$ & $0.12 \pm 0.12(221)$ & $0.04 \pm 0.22(732)$ & $0.11 \pm 0.17$ & $0.08 \pm 0.32(266)$ \\
\hline Aug (+167.2) & $0.05 \pm 0.23(838)$ & $0.16 \pm 0.17(165)$ & $0.31 \pm 0.35$ & $0.08 \pm 0.16(604)$ & $0.16 \pm 0.13(486)$ & $0.26 \pm 0.41(588)$ \\
\hline Sep $(+197.6)$ & $0.12 \pm 0.25(952)$ & $0.11 \pm 0.26$ & $0.24 \pm 0.22(703)$ & $0.03 \pm 0.28(647)$ & $0.10 \pm 0.21$ & $0.03 \pm 0.23(241)$ \\
\hline Oct $(+228)$ & $0.11 \pm 0.22(786)$ & $0.24 \pm 0.19(102)$ & $0.21 \pm 0.39(341)$ & $0.14 \pm 0.14$ & $0.36 \pm 0.14(159)$ & $0.14 \pm 0.19$ \\
\hline Nov $(+258.4)$ & $0.15 \pm 0.20(725)$ & $0.27 \pm 0.24(121)$ & $0.37 \pm 0.22(196)$ & $0.17 \pm 0.18(602)$ & $0.19 \pm 0.18$ & $0.24 \pm 0.26(255)$ \\
\hline Dec (+288.8) & $0.11 \pm 0.29(847)$ & $0.26 \pm 0.21(136)$ & $0.39 \pm 0.43(527)$ & $0.26 \pm 0.34(910)$ & $0.09 \pm 0.26(705)$ & $0.11 \pm 0.35$ \\
\hline $\operatorname{Jan}(+319.2)$ & $0.19 \pm 0.35(643)$ & $0.10 \pm 0.30(161)$ & $0.37 \pm 0.45(407)$ & $0.18 \pm 0.22$ & $0.01 \pm 0.31$ & $0.46 \pm 0.72(516)$ \\
\hline
\end{tabular}


2011
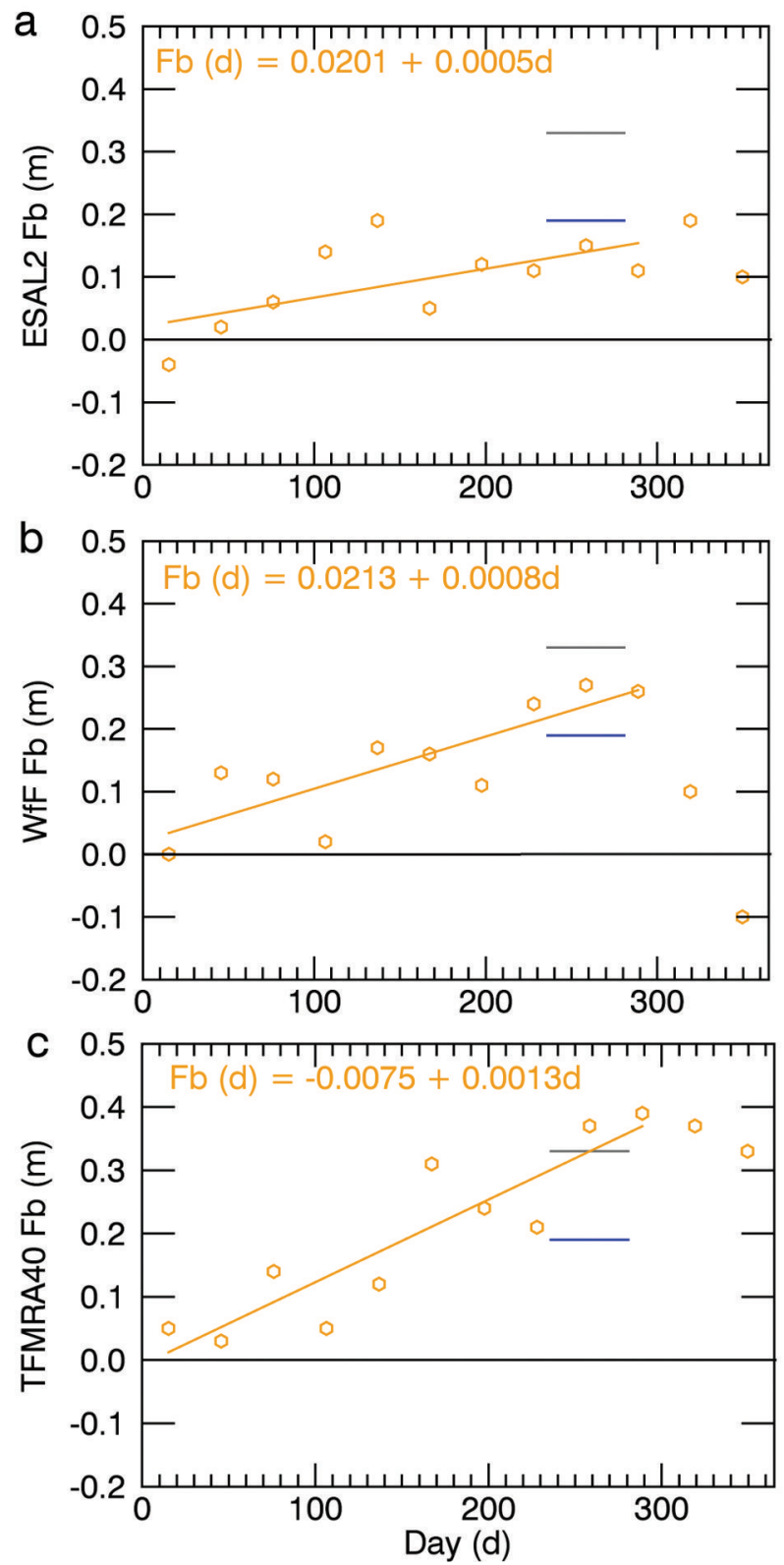

2013
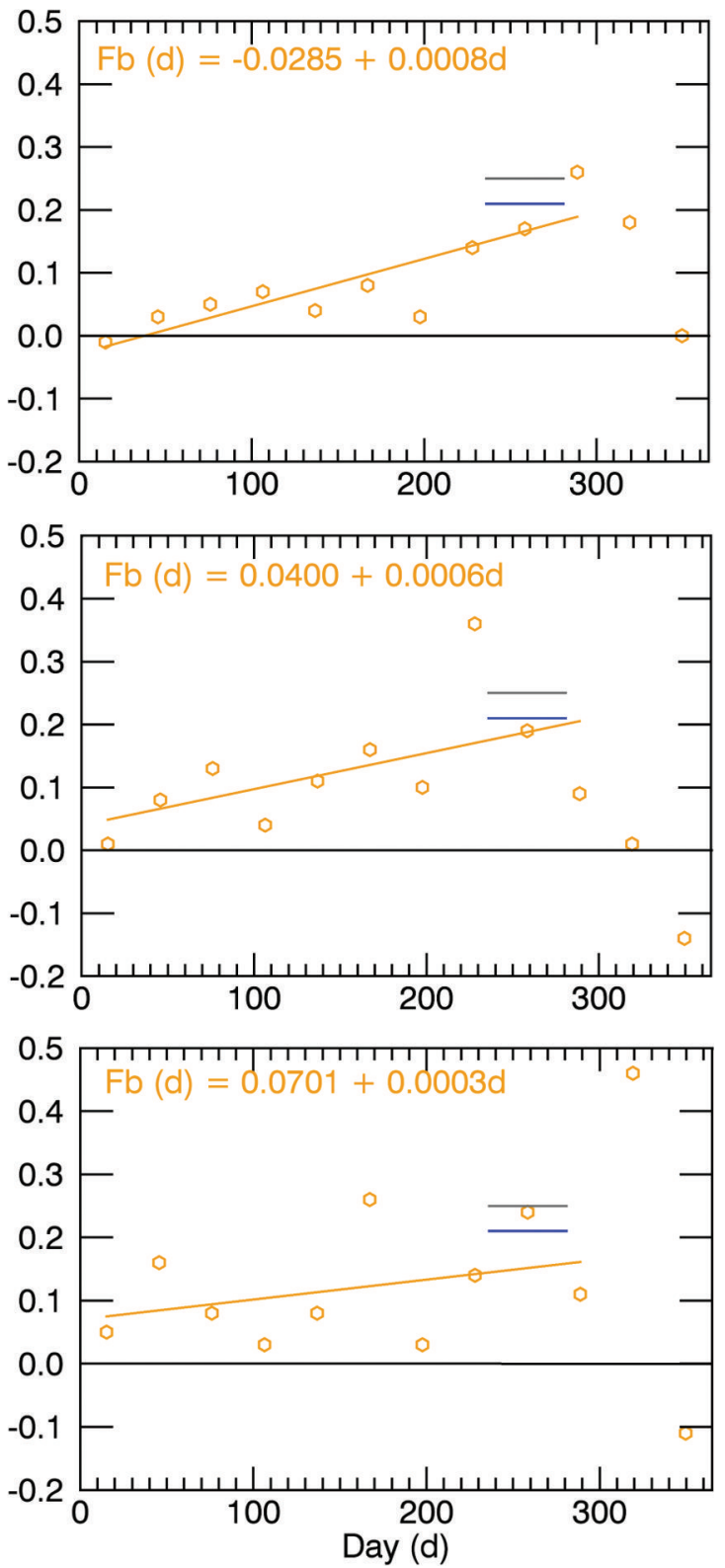

Fig. 8. The development of the McMurdo Sound fast-ice cover from mean automatic procedure freeboard values for each month for 2011 and 2013 over the expected sea-ice growth period (day zero = 1 March) for ESAL2 (a), WfF (b) and TFMRA40 (c). A linear fit from the beginning of mid-March ( day 15) to mid-December ( day 290) defines the expected sea-ice growth period. Mean in situ measured ice and snow freeboards measured in November/December of each year are shown by the blue and grey lines respectively. The standard deviations for each mean value are provided in Table 3.

ESAL2, WfF and TFMRA40 using a supervised SSH identification with the exception of WfF in 2011. For the latter, we attribute the anomalously high freeboard to two sources. The first is a low SSH estimate due to the reduced ability of the technique to establish $\mathrm{SSH}$ in the presence of differing surface types over a small segment of the SSH reference area. Secondly the introduction of a positive freeboard bias is noted which is forced by a smoother, thicker and morphologically more complex snow cover in 2011. These findings are supportive of other studies (Kurtz and others, 2014; Kwok, 2014) which also show that snow can introduce a positive elevation bias due to an increase in power returned from above the snow/ice interface. We also observe a higher $\mathrm{Fb}_{\text {sup }}$ for ESAL2 in 2011 when compared to 2013, and suggest a similar response to the change in snow properties has influenced the retrieval. Our observations show that the snow in the study area has higher mean densities and exhibits distinct layers with varying hardness, density and crystal size, as compared with the simplified assumptions in Kurtz and others (2014). It is speculated that in combination with the larger grain size and higher salinity near the snow/ ice interface, the effective point of scattering is shifted even further away from the ice surface. The only way to quantify what impact the snow cover had on the retrieved freeboards would be to know the backscatter coefficients of the snow and ice. Lacking this information we are limited to more qualitative statements based on comparisons to in situ information. Our ability to convey qualitative information on the waveform interaction at the surface, as suggested in Section 4, is also restricted. In the presence of a snow cover that is fully transparent to the incident Ku-band radar energy, no bias is expected to be observed for retracking procedures. 
Attaining knowledge of the dominant backscattering surface is crucial to undertake any meaningful time-series assessment of sea-ice freeboard, permitting thickness estimation. Therefore the role of the heterogeneity of the snow cover on CS-2 freeboard retrieval requires further observational study.

Although we observe the influence of the snow cover in the freeboard retrieval, we are unable to fully quantify the error in the SSH identification, even under the supervised assessment. Experiments in which the influence of $\mathrm{SSH}$ misidentification is isolated will need to be carried out to completely quantify the positive bias introduced by a snow cover using WfF. In addition, the use of automatic SSH identification procedures can be expected to increase freeboard errors. Direct comparisons between supervised and automatic procedures suggest differences in excess of $0.05 \mathrm{~m}$.

It was not possible to determine the accuracy of the established $\mathrm{SSH}_{\text {sup }}$ and we can only evaluate the resulting freeboards. The $\mathrm{SSH}_{\text {sup }}$ of all three data products was independently assessed without tuning to in situ measured freeboards. However, the characteristics of the study area made it necessary to modify the processing methods for sea surface identification currently used in the Arctic (Kurtz and others, 2014; Ricker and others, 2014). The surface type polynya was added to the surface classification for TFMRA4O to improve ice-water discrimination. This surface type produces similar waveforms to sea ice, but more diffuse, with a leading edge that is typically flatter. The power threshold for retracking over this surface type was increased to $60 \%$. The fact that larger open-water areas can result in significantly different $\mathrm{SSH}$ estimates may introduce a significant inter-retracker difference in $\mathrm{SSH}$ establishment due to the inconsistent change along the leading edge. Future improvement of the WfF technique over varying surface types in close proximity (i.e. leads, open water, seaice floes within a few hundred meters) is required. These conditions cause noisy waveforms, and improvement of our understanding of the influence of this noise on the retracking procedure is a current research focus. It seems that the more sophisticated approach of WfF is more sensitive to these conditions than TFMRA40, and a more stringent data discard procedure may need to be adopted to reject such waveforms. Further, using automatic surface discrimination algorithms resulted in insufficient separation of sea-ice and water surface types. It may be of benefit to adopt procedures that account for the seasonal change in sea-ice/snow surface conditions which force alteration of surface discriminatory parameters (e.g. $P, P P$, SSD). This may improve the separation of surface types and $\mathrm{Fb}_{\text {auto }}$ results, both in this investigation area and when larger regions are considered for assessment.

With the aid of information gained in the supervised freeboard retrieval procedure, we were able to place in context and develop automatic freeboard retrieval procedures for each technique. Our results have shown the ability of CS-2 to record the development of a fast-ice cover in the Antarctic. Although our supervised analysis provides insight into the surface that is tracked with respect to $\mathrm{Fb}_{\mathrm{s}}$ and $\mathrm{Fb}_{\mathrm{i}}$ we do not have the confidence to estimate sea-ice thickness with an acceptable error margin. However, we do find the growth rate as recorded by $\mathrm{Fb}_{\text {auto }}$ over both years for all techniques, of $0.7 \mathrm{~mm} \mathrm{~d}^{-1}$ (mean of all rates displayed in Fig. 8), is in agreement with other studies of ice growth rates in McMurdo Sound (Purdie and others, 2006; Gough and others, 2012). By April, all retracking techniques identify positive freeboard values. Although we identify the onset and the trend in freeboard growth, we note that standard deviations of $\mathrm{Fb}_{\text {auto }}$ are typically twice that found over this area when it was assessed using ICESat from 2003 to 2009 (Price and others, 2013). There was an extensive multi-year sea-ice cover in McMurdo Sound from 2003 to 2009. However, we are not aware of any changes to the FY sea-ice surface conditions between the two satellite observation periods that could be responsible for the observed differences in standard deviations, although the CS-2 assessment area is smaller. Therefore, it is appropriate to look to instrumental and methodological sources to explain the observed noise. Findings from CS-2 presented here were attained using SIN mode which acquires data at a reduced (by a factor of four) burst repetition interval compared to SAR mode which is used over the majority of the Antarctic sea-ice pack. The ability to average and reduce measurement noise in the SIN mask which occupies the entire coastal Antarctic, a key area of sea-ice production, is therefore reduced. Assuming normally distributed noise, the values for the standard deviations would reduce by a factor of two if data were acquired in SAR mode. Even with this restriction, there is no evidence that SIN mode is inadequate for sea-ice freeboard retrieval. Other studies (Armitage and Davidson, 2014) provide evidence in support of its usage, as SIN mode provides phase information which can be used to reduce the impact of snagging on height retrievals. This ability is beneficial, as a less stringent data discard is required to remove off-nadir range estimates which exhibit a positive range bias and subsequently height retrievals that are too low. The standard deviations of $\mathrm{Fb}_{\text {auto }}$ using TFMRA40 are higher than those from the other two procedures, perhaps an indication of the noise introduced from the range bias as a result of omitting phase information. An additional source of scatter and an increased standard deviation could be introduced to the TFMRA4O procedure, as the slope of the leading edge at the tracking point is typically shallower in comparison to higher thresholds. This could force a higher noise if waveforms change significantly from one measurement to the next. The noise in TFMRA4O heights could also indicate that undulations or roughness of the snow surface was often higher than the ice surface beneath. These factors do not seem to have been influential along the validation line (Fig. 4), where TFMRA40 produced the least noisy $\mathrm{Fb}_{\text {sup }}$ dataset of the three techniques.

The surface height that is tracked is dependent upon where on the leading edge each processor establishes its retracking point, which is selected on the basis of the assumed dominant backscattering interface (e.g. retracking at $40 \%, 40-70 \%$ or $50-90 \%)$. This is a trivial consideration and, in the absence of any alteration of the waveform by surface conditions, these simple differences in range would cause the resultant differences in measured freeboard. Our results show that in McMurdo Sound using the supervised analysis in an optimal scenario, when there is a thin and homogeneous snow cover (mean $=0.05 \mathrm{~m}$ ), TFMRA40 approximates $F_{\mathrm{s}}$ well, WfF approximates $F_{\mathrm{i}}$ well, and ESAL2 identifies a horizon in between $F_{\mathrm{i}}$ and $F_{\mathrm{s}}$. Although we have identified that GR, RR and snow are influential on the leading edge, we cannot separate their influence with any certainty. It is evident from interpretation of the leading edge alone that no separation of the air/snow interface and ice/snow interface is directly achievable, which is expected due to 
the range resolution of CS-2 (Wingham and others, 2006; Bouzinac, 2013; Kurtz and others, 2014; Kwok, 2014). However, using a comparison between a snow-covered seaice area and an area with significantly less snow, the gradient of the leading edge becomes shallower and the width of the entire waveform is extended in the presence of snow. Based on the model assumptions of WfF, very small changes in the leading edge are expected as a function of surface roughness, and insufficiencies in the fit of the leading edge as shown in Figure $6 \mathrm{~b}$ indicate a higher than expected influence of roughness and snow cover on the leading edge. This will alter the retracking position on the leading edge for every retracker in a different way. It is therefore reasonable to conclude that not only the trivial relationship of different retracking points is responsible for the observed differences in freeboards between methods, but variations in surface properties were also influential. Further work is required to separate and quantify these influences.

Relating our findings to the development of larger-scale Antarctic assessments outside the coastal band is hindered by the nature of our study area compared to the majority of the Antarctic sea-ice pack. However, the dynamic sea-ice area in the MSP is more representative of the wider Antarctic sea-ice zone. Although this area was not the focus of our assessment, automatic freeboard retrieval procedures which included this area have produced freeboards that are considered reasonable for Antarctic pack ice, i.e. 0.08$0.16 \mathrm{~m}$ (Table 2). We have identified certain issues within our analysis which are applicable at the larger scale which must be addressed in order to develop techniques. Given the abundance of large open-water areas in the Antarctic sea-ice zone which do not exhibit the typical 'peaky' response from leads, it is necessary to characterize them. If they are large enough and their sea-ice concentration is low, they can be masked using auxiliary satellite information. However, in regions of high ice concentration where leads are too large to be discernible from radar information, icewater discrimination may be hindered. At what size a lead becomes too large to exhibit a typical waveform would need to be ascertained to conclude whether open-water areas may be an issue in the Antarctic sea-ice pack. The spatial and temporal heterogeneity of the snow cover, even in our small study area, highlights the challenge presented for freeboard retrieval algorithms to assess larger areas in the Antarctic. Further advances in retracking techniques guided by in situ validation will need to be made in order to attain freeboard measurements with improved accuracy. Further complications will be introduced by snow loading which typically suppresses sea-ice freeboard, resulting in a close to zero ice freeboard condition in the Antarctic sea-ice pack. This issue may be addressed using a combination of different retracking procedures that attempt to identify the air/snow interface as shown to be successful here. In any case, it is clear that data treatment may need to be altered for different regions, in particular retracker algorithms to cater for the variability of the Antarctic sea-ice regime.

\section{CONCLUSION}

Our in situ freeboard measurements reveal that retracking techniques based on the fitting of waveforms (ESAL2 and $W f F)$ and a threshold retracker (TFMRA40) can be used to derive freeboard estimates over Antarctic fast ice from CS-2. Although we find that the retrievals capture freeboard heights, the variability is expected to be high as indicated by the large standard deviations of mean freeboard values. In the validation area of McMurdo Sound, which harbors homogeneous fast ice, the results of the three separate techniques used for freeboard retrieval fall within the margins of expected freeboards as indicated by in situ measurements in austral spring 2011 and 2013. Mean freeboard values from ESAL2 are representative of a horizon between the air/snow and snow/ice interface. A smooth snow cover with multiple layers causes a bias of $+0.14 \mathrm{~m}$ away from the ice freeboard using WfF. It should be noted that we are unable to identify any contribution from an inaccurate sea surface height establishment upon this bias. In the absence of such a snow cover, WfF-derived freeboards are $0.04 \mathrm{~m}$ lower than in situ measured ice freeboard. TFMRA40 produces mean freeboards $0.03 \mathrm{~m}$ higher than in situ measured snow freeboard. We observe higher standard deviations in automatic retrieval procedures, which could be reduced by spatial averaging if data at a higher sampling rate (e.g. in SAR mode) were available. Difficulties in the identification of sea surface height were noted for TFMRA4O over larger open-water areas and for WfF over areas inclusive of multiple surface types (e.g. leads, sea ice and open water) within the radar footprint. Automatic algorithms were tested through 2011 and 2013 and recorded the growth of the FY fast-ice cover in McMurdo Sound. The CS-2 trends recorded from each method of $0.7 \mathrm{~mm} \mathrm{~d}^{-1}$ are in line with sea-ice growth rates measured in situ in the region. Automatic surface type discrimination procedures may benefit from adjustments to account for spatial and temporal variations in snow/ice surface conditions, which could improve ice-water discrimination. In situ validation in the Antarctic pack ice is a fundamental component for the development of CS-2 freeboard retrieval techniques. The uncertainty of CS-2 freeboard datasets is expected to be improved over larger spatial scales than assessed here. We see our results as encouraging in this context, as expansion of spatial scales and further development of retracking techniques will likely improve Antarctic CS-2 freeboard products.

\section{ACKNOWLEDGEMENTS}

We thank all participants in the 2011 and 2013 Antarctica New Zealand field event K063 as well as Scott Base staff for their support. CS-2 data were provided by the European Space Agency for project AOCRY2CAL-4512. The TerraSAR-X image was provided through DLR (German Aerospace Center) project OCE1592. The work of V. Helm and S. Hendricks was funded by the German Ministry of Economics and Technology (grant 50EE1008). We appreciate the efforts of Alec Casey who provided technical assistance in data processing. A research stay for the first author at the University of Alberta was supported by Air New Zealand. Further research support was provided by the National Institute of Water and Atmospheric Research, New Zealand, under contract CO1X1226. We thank Trimble NZ for the use of GNSS equipment, and Wolfgang Dierking for fruitful discussions. We are very grateful for the contributions of Nick Key and Justin Harrison in the design and preparation of field equipment. The comments of two anonymous reviewers and the sea-ice editor contributed to the manuscript. This work was collated at Gateway Antarctica, University of Canterbury, New Zealand. 


\section{REFERENCES}

Alexandrov V, Sandven S, Wahlin J and Johannessen OM (2010) The relation between sea ice thickness and freeboard in the Arctic. Cryosphere, 4, 373-380 (doi: 10.5194/tc-4-373-2010)

Armitage TWK and Davidson MWJ (2014) Using the interferometric capabilities of the ESA CryoSat-2 Mission to improve the accuracy of sea ice freeboard retrievals. IEEE Trans. Geosci. Remote Sens., 52, 529-536 (doi: 10.1109/TGRS.2013.2242082)

Barber DG, Reddan SP and Ledrew EF (1995) Statistical characterization of the geophysical and electrical properties of snow on landfast first-year sea ice. J. Geophys. Res., 100(C2), 2673-2686 (doi: 10.1029/94JC02200)

Beaven SG and 8 others (1995) Laboratory measurements of radar backscatter from bare and snow-covered saline ice sheets. Int. J. Remote Sensing, 16, 851-876 (doi: 10.1080/ 01431169508954448)

Bintanja R, Van Oldenborgh GJ, Drijfhout SS, Wouters B and Katsman CA (2013) Important role for ocean warming and increased ice-shelf melt in Antarctic sea-ice expansion. Nature Geosci, 6, 376-379 (doi: 10.1038/ngeo1767)

Bouzinac C (2013) CryoSat product handbook. https://earth.esa.int/ documents/10174/125272/CryoSat_Product_Handbook

Dempsey DE, Langhorne PJ, Robinson NJ, Williams MJM, Haskell TG and Frew RD (2010) Observation and modelling of platelet ice fabric in McMurdo Sound, Antarctica. J. Geophys. Res., 115(C1), C01007 (doi: 10.1029/2008JC005264)

Drinkwater, M. (1991) Ku-band airborne radar altimeter observations of marginal sea ice during the 1984 Marginal Ice Zone Experiment. J. Geophys. Res., 96(C3), 4555-4572

Drinkwater MR, Francis R, Ratier G and Wingham DJ (2004). The European Space Agency's Earth Explorer Mission CryoSat: measuring variability in the cryosphere. Ann. Glaciol., 39, 313-320 (doi: dx.doi.org/10.3189/172756404781814663)

Fedotov VI, Cherepanov NV and Tyshko KP (1998) Some features of the growth, structure and metamorphism of East Antarctic landfast sea ice. In Jeffries MO ed. Antarctic sea ice: physical processes, interactions and variability. (Antarctic Research Series 74) American Geophysical Union, Washington, DC (doi: 10.1029/AR074p0343)

Fraser AD, Massom RA, Michael KJ, Galton-Fenzi BK and Lieser JL (2011) East Antarctic Landfast sea ice distribution and variability, 2000-08. J. Climate, 25, 1137-1156 (doi: dx.doi.org/ 10.1175/JCLI-D-10-05032.1)

Gough AJ, Mahoney AR, Langhorne PJ, Williams MJM, Robinson NJ and Haskell TG (2012) Signatures of supercooling: McMurdo Sound platelet ice. J. Glaciol., 58(207), 38-50 (doi: dx.doi.org/ 10.3189/2012JoG10J218)

Gow AJ, Ackley SF, Govoni JW and Weeks WF (1998) Physical and structural properties of land-fast sea ice in McMurdo Sound, Antarctica. In Jeffries $\mathrm{MO}$ ed. Antarctic sea ice: physical processes, interactions and variability. (Antarctic Research Series 74) American Geophysical Union, Washington, DC, 355-374

Hallikainen MT, Ulaby F and Abdelrazik M (1986) Dielectric properties of snow in the 3 to $37 \mathrm{GHz}$ range. IEEE Trans. Antennas Propag., 34(11), 1329-1340

Heine AJ (1963) Ice breakout around the southern end of Ross Island, Antarctica. New Zeal. J. Geol. Geophys., 6(3), 395-401

Hellmer HH (2004) Impact of Antarctic ice shelf basal melting on sea ice and deep ocean properties. Geophys. Res. Lett., 31(10), L10307 (doi: 10.1029/2004GL019506)

Helm V, Humbert A and Miller H (2014) Elevation and elevation change of Greenland and Antarctica derived from CryoSat-2. Cryosphere, 8, 1539-1559 (doi: 10.5194/tc-8-1539-2014)

Hendricks S, Stenseng L, Helm V and Haas C (2010) Effects of surface roughness on sea ice freeboard retrieval with an Airborne $\mathrm{Ku}$-Band SAR radar altimeter. In International Geoscience and Remote Sensing Symposium (IGARSS 2010), 25-30 July 2010. Proceedings. Institute of Electrical and Electronics Engineers, Piscataway, NJ, 3126-3129
Holland PR, Bruneau N, Enright C, Losch M, Kurtz NT and Kwok R (2014) Modelled trends in Antarctic sea ice thickness. J. Climate, 27, 3784-3801 (doi: dx.doi.org/10.1175/JCLI-D-13-00301.1)

Jeffries MO, Weeks WF, Shaw R and Morris K (1993) Structural characteristics of congelation and platelet ice and their role in the development of Antarctic land-fast sea ice. J. Glaciol., 39(132), 223-238

Kurtz NT and Markus T (2012) Satellite observations of Antarctic sea ice thickness and volume. J. Geophys. Res., 117(C8), C08025 (doi: 10.1029/2012JC008141)

Kurtz NT, Galin N and Studinger M (2014) An improved CryoSat-2 sea ice freeboard retrieval algorithm through the use of waveform fitting. Cryosphere, 8, 1217-1237 (doi: 10.5194/tc8-1217-2014)

Kwok R (2014). Simulated effects of a snow layer on retrieval of CryoSat-2 sea ice freeboard. Geophys. Res. Lett., 41, 5014-5020 (doi: 10.1002/2014GL060993)

Laxon SW and 14 others (2013) CryoSat-2 estimates of Arctic sea ice thickness and volume. Geophys. Res. Lett., 40, 732-737 (doi: 10.1002/grl.50193)

Leonard GH, Purdie CR, Langhorne PJ, Haskell TG, Williams MJM and Frew RD (2006) Observations of platelet ice growth and oceanographic conditions during the winter of 2003 in McMurdo Sound, Antarctica. J. Geophys. Res., 111(C4), C04012 (doi: 10.1029/2005JC002952)

Mahoney AR and 6 others (2011) The seasonal appearance of ice shelf water in coastal Antarctica and its effect on sea ice growth. J. Geophys. Res., 116(C11), C11032 (doi: 10.1029/ 2011JC007060)

Massom R, Harris P, Michael KJ and Potter M (1998) The distribution and formative processes of latent-heat polynyas in East Antarctica. Ann. Glaciol., 27, 420-426

Massom RA and 13 others (2001) Snow on Antarctic sea ice. Rev. Geophys., 39, 413-445

Massonnet F and 6 others (2013) A model reconstruction of the Antarctic sea ice thickness and volume changes over 19802008 using data assimilation. Ocean Model., 64, 67-75 (doi: 10.1016/j.ocemod.2013.01.003)

Ozsoy-Cicek B, Ackely S, Xie H, Yi D and Zwally J (2013) Sea ice thickness retrieval algorithms based on in situ surface elevation and thickness values for application to altimetry. J. Geophys. Res., 118, 3807-3822 (doi: 10.1002/jgrc.20252)

Parkinson CL and Cavalieri DJ (2012) Antarctic sea ice variability and trends, 1979-2010. Cryosphere, 6, 871-880 (doi: 10.5194/ tc-6-871-2012)

Peacock NR and Laxon S (2004) Sea surface height determination in the Arctic Ocean from ERS altimetry. J. Geophys. Res., 109(C7), C07001 (doi: 10.1029/2001JC001026)

Price D, Rack W, Haas C, Langhorne PJ and Marsh O (2013) Sea ice freeboard in McMurdo Sound, Antarctica, derived by surface-validated ICESat laser altimeter data. J. Geophys. Res., 118(7), 3634-3650 (doi: 10.1002/jgrc.20266)

Price D, Rack W, Langhorne PJ, Haas C, Leonard G and Barnsdale K (2014) The sub-ice platelet layer and its influence on freeboard to thickness conversion of Antarctic sea ice. Cryosphere, 8, 1031-1039 (doi: 10.5194/tc-8-1031-2014)

Purdie CR, Langhorne PJ, Leonard GH and Haskell TG (2006) Growth of first-year landfast Antarctic sea ice determined from winter temperature measurements. Ann. Glaciol., 44, 170-176 (doi: 10.3189/172756406781811853)

Ricker R, Hendricks S, Helm V, Skourup H and Davidson M (2014) Sensitivity of CryoSat-2 Arctic sea-ice volume trends on radarwaveform interpretation. Cryosphere Discuss., 8, 1831-1871 (doi: 10.5194/tcd-8-1831-2014)

Smith IJ, Langhorne PJ, Frew RD, Vennell R and Haskell TG (2012) Sea ice growth rates near ice shelves. Cold Reg. Sci. Technol., 83-84, 57-70 (doi: 10.1016/j.coldregions.2012.06.005)

Tamura T, Ohshima KI and Nihashi S (2008) Mapping of sea ice production for Antarctic coastal polynyas. Geophys. Res. Lett., 35(7), L07606 (doi: 10.1029/2007GL032903) 
Tiuri ME, Sihvola AH, Nyfors E and Hallikaiken M (1984) The complex dielectric constant of snow at microwave frequencies. IEEE J. Ocean. Eng., 9, 377-382

Ulaby FT, Moore RK and Fung AK (1982) Physical mechanisms and empirical models for scattering and emission. In Microwave remote sensing: active and passive. Vol. II: Radar remote sensing and surface scattering and emission theory. Addison-Wesley Publishing Co., Reading, MA

Ulaby F, Moore RK and Fung AK (1986) Microwave remote sensing: active and passive. Vol. III. Artech House, Dedham, MA

Vaughan DG and 13 others (2013) Observation: cryosphere. In Stocker TF and 9 others eds Climate change 2013: the physical science basis. Contribution of Working Group I to the Fifth Assessment Report of the Intergovernmental Panel on Climate Change. Cambridge University Press, Cambridge and New York

Willatt RC, Giles KA, Laxon SW, Stone-Drake L and Worby AP (2010) Field investigations of $K u$-band radar penetration into snow cover on Antarctic sea ice. IEEE Trans. Geosci. Remote Sens., 48, 365-372
Wingham DJ, Phalippou L, Mavrocordatos C and Wallis D (2004) The mean echo and echo cross product from a beamforming interferometric altimeter and their application to elevation measurement. IEEE Trans. Geosci. Remote Sens., 42(10), 2305-2323 (doi: 10.1109/tGrs.2004.834352)

Wingham DJ and 15 others (2006) CryoSat: a mission to determine the fluctuations in Earth's land and marine ice fields. Adv. Space Res., 37, 841-871 (doi: 10.1016/j.asr.2005.07.027)

Xie H, Tekeli AE, Ackley SF, Yi D and Zwally HJ (2013) Sea ice thickness estimations from ICESat altimetry over the Bellingshausen and Amundsen Seas, 2003-2009. J. Geophys. Res., 118(5), 2438-2453 (doi: 10.1002/jgrc.20179)

Yi D, Zwally HJ and Robbins JW (2011) ICESat observations of seasonal and interannual variations of sea-ice freeboard and estimated thickness in the Weddell Sea, Antarctica (20032009). Ann. Glaciol., 52(57 Pt 1), 43-51 (doi: 10.3189/ 172756411795931480

Zwally HJ, Yi D, Kwok R and Zhao Y (2008) ICESat measurements of sea ice freeboard and estimates of sea ice thickness in the Weddell Sea. J. Geophys. Res., 113(C2), C02S15 (doi: 10.1029/ 2007JC004284)

MS received 18 August 2014 and accepted in revised form 9 January 2015 